$\oint_{\text {doi: } 10.3765 / \text { sp.3.6 }}^{\text {Semantics \& Pragmatics Volume 3, Article 6: 1-54, } 2010}$

\title{
The semantics and pragmatics of plurals
}

\author{
Donka F. Farkas \\ Henriëtte E. de Swart \\ Department of Linguistics, \\ University of California at Santa Cruz
Department of Modern Languages, Utrecht University

Received 2008-11-14 / First Decision 2009-01-23 / Revised 2009-04-28 / Second Decision 2009-07-07 / Revised 2009-09-18 / Third Decision 2009-10-07 / Revised 2009-10-30 / Accepted 2009-11-21 / Final Version Received 2010-01-o6 / Published 2010-03-30

\begin{abstract}
This paper addresses the semantics and pragmatics of singular and plural nominals in languages that manifest a binary morphological number distinction within this category. We review the main challenges such an account has to meet, and develop an analysis which treats the plural morpheme as semantically relevant, and the singular form as not contributing any number restriction on its own but acquiring one when in competition with the plural form. The competition between singular and plural nominals is grounded in bidirectional optimization over form-meaning pairs. The main conceptual advantage our proposal has over recent alternative accounts is that it respects Horn's 'division of pragmatic labor', in that it treats morphologically marked forms as semantically marked, and morphologically unmarked forms as semantically unmarked. In our account, plural forms are polysemous between an exclusive plural sense, which enforces sum reference, and an inclusive sense, which allows both atoms and sums as possible witnesses. The analysis predicts that a plural form is pragmatically appropriate only in case sum values are among the intended referents. To account for the choice between these two senses in context we invoke the Strongest Meaning Hypothesis, an independently motivated pragmatic principle. Finally, we show how the approach we develop explains some puzzling contrasts in number marking between English three/more children and Hungarian három/több gyerek ('three/more child'), a problem that has not been properly accounted for in the literature so far.
\end{abstract}

Keywords: singular, plural, morphology, markedness, optimality theory, strongest meaning hypothesis, Hungarian

(C)2010 Farkas and de Swart

This is an open-access article distributed under the terms of a Creative Commons NonCommercial License (creativecommons.org/licenses/by-nc/3.o). 
Farkas and de Swart

\section{Atoms, sums and the inclusive/exclusive sum interpretation}

\subsection{Inclusive and exclusive interpretations of the plural}

The question addressed in this paper is a simple one: What is the difference in meaning between singular and plural nominals in languages such as English, where this distinction is morphologically marked? ${ }^{1}$ The issue then is to characterize the semantic difference between the pair in (1), as it pertains to information conveyed by the contrast in number.

a. Mary saw a horse.

b. Mary saw horses.

A disarmingly simple answer would be to say that singular nominals (such as $a$ horse above) refer to one entity while plural nominals (such as horses) refer to more than one entity. Recast in more technical terms based on Link (1983), this answer is formulated in (2):

(2) a. Singular nominals refer within the domain of atoms.

b. Plural nominals refer within the domain of sums.

In Link's proposal, the domain of entities from which nominals take values has the structure of a join-semilattice whose atoms are ordinary individuals (in this case individual horses) and whose non-atomic elements are all the possible sums of more than one atom (in this case groups of more than one horse). Under the simple view, when a nominal is singular, the domain from which its referent is chosen is the set of atoms in the semilattice denoted by its head noun, while in case it is plural, its reference domain is the set of sums in that semilattice.

1 We use nominal here as a cover term for DPs and NPs. We limit the discussion to nominals in regular argument position, and ignore special uses in predication, incorporation, etc. (cf. de Swart \& Zwarts 2009 and references therein for discussion of such constructions). Among the languages that manifest a singular/plural morphological distinction are the languages within the Germanic and Romance families as well as Finno-Ugric languages such as Hungarian and Finnish. We will not deal here with languages that make more fine-grained distinctions in number, involving duals or paucals (see Corbett 2000). Languages such as Mandarin Chinese that lack morphological number distinctions are briefly taken into consideration below but do not receive a full-fledged analysis in this paper but see Krifka (1995) and Rullmann (2003) for relevant proposals. Nor do we go into issues concerning non-morphological encoding of number information of the type discussed for Korean by Kwon \& Zribi-Hertz (2006) or for Papiamentu and Brazilian Portuguese by Kester \& Schmitt (2007). 
Singulars and Plurals

The interpretation of the plural nominal in (1b) is labelled exclusive because its reference is restricted to sums, excluding atoms: (1b) is interpreted as claiming that Mary saw more than one horse. The classical challenge for the naïve view of the semantics of the plural is the existence of so-called inclusive plurals, exemplified in (3a-c). These are plural forms whose interpretation appears to be indifferent to the atom/sum divide in that the plural nominal is allowed to range over both atoms and sums.

a. Have you ever seen horses in this meadow?

b. If you have ever seen horses in this meadow, you should call us.

c. Sam has never seen horses in this meadow.

Thus, a yes answer to (3a) normally commits the speaker to having seen one or more horses; in (3b), the addressee is expected to call even if she has seen a single horse in the meadow, and (3c) is judged false in case Sam has seen a single horse in the meadow. The existence of inclusive readings comes as an unpleasant surprise to the naïve view, which predicts that the plural forms in (3a)-(3c) are interpreted exclusively, just like the plural in (1b).

Note next that even though plurals may receive an inclusive interpretation in questions and within the scope of negation, as shown in (3a-c), the distinction between singulars and plurals is not fully obliterated in these environments. This is illustrated by (4a) and (4b) taken from Farkas (2006) and Spector (2007) respectively, who note that the plural is distinctly odd in these examples because normally people have only one nose and only one father.

(4) a. Does Sam have a Roman nose/\#Roman noses?

b. Jack doesn't have a father/\#fathers.

The contrast between $(3 a-c)$ and ( $4 a-b)$ shows that a plural form remains sensitive to the atom/sum distinction, even in environments where it can be interpreted inclusively. A plural is always odd when sum values are pragmatically excluded from its domain of reference. Ideally, this property should follow from the account of the semantics and pragmatics of number interpretation without any specific stipulations.

So far then we have established that an account of number interpretation has to explain why plural forms are susceptible to both exclusive and inclusive readings, and furthermore, one has to understand why particular linguistic environments favor one or the other shade of meaning, while at the same time predicting the sensitivity of plural forms to sum reference in all contexts. In 
the rest of this section we establish some further conceptual and empirical challenges an adequate account of number must meet and discuss some of the most influential previous ways of dealing with them.

In Section 2, which contains the core of our proposal, we give a semantics for the singular/plural contrast. In keeping with facts about overt morphology in the languages under consideration, we do not make use of a singular morpheme and therefore do not assign singular forms any inherent 'singular' semantics. The plural morpheme on the other hand is treated as contributing a polysemous meaning, with the inclusive and exclusive interpretations being its two related senses. The atomic reference of the singular comes about in our account as a result of the competition between singular and plural forms in the spirit of previous analyses but starting from opposite assumptions. This competition is modelled in bidirectional Optimality Theory.

In Section 3 we account for the inclusive/exclusive interplay exemplified by the contrast between (1b) and (3a-c) by exploiting the Strongest Meaning Hypothesis, an independently motivated pragmatic principle. We also show that the analysis we propose predicts that a plural form always requires the possibility of sum witnesses, thus explaining the contrast in (4a-b) without any extra stipulation. Section 4 shows how the analysis of languages like English extends to an apparent puzzling use of singular forms with sum reference in Hungarian, while Section 5 sums up the results of the paper.

\subsection{The strong singular/weak plural view}

An immediate solution to the inclusive plural problem illustrated in (3a-c) is sketched in Krifka 1989. Plural forms, he suggests, are semantically indifferent to the atom/sum distinction while singular forms involve number semantics that imposes atomic reference. In this view, the plural is semantically "weak" in that it has no semantic contribution. The singular on the other hand, is semantically "strong" in that it imposes an atomic reference requirement. The 'exclusive' interpretation of the plural in sentences like ( $1 \mathrm{~b}$ ) is due, in Krifka's view, to a pragmatic blocking effect. The existence of the semantically strong singular form blocks the use of the semantically weak plural when atomic reference is intended because of a pragmatic rule that forces the choice of a more specific form over a less specific one when the two are equally complex. Since a singular nominal is more specific than its plural counterpart, the singular has to be chosen whenever atomic reference is meant, thus excluding an atomic interpretation for plural forms. 
Singulars and Plurals

This idea is worked out in detail in Sauerland 2003 and Sauerland, Anderssen \& Yatsushiro 2005. In Sauerland et al. 2005, there are two number features, SG and PL, located syntactically in the head of a $\phi P$ node, as in figure 1 , where *boy is a number-neutral predicate, insensitive to the atom/sum distinction:

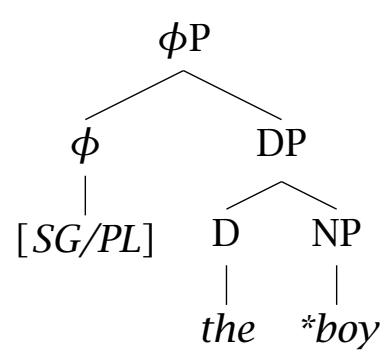

Figure 1 Number features in Sauerland et al. 2005

The proposed semantic contribution of the two number features is given in (5):

(5) Semantics of the singular/plural in Sauerland et al. 2005:

a. $\llbracket \operatorname{SING} \rrbracket(\mathrm{x})$ is defined only if $\# x=1$

$\llbracket \mathrm{SING} \rrbracket(\mathrm{x})=\mathrm{x}$ wherever it is defined

b. $\llbracket P L U R \rrbracket(x)$ is always defined

$\llbracket \operatorname{PLUR} \rrbracket(\mathrm{x})=\mathrm{x}$ wherever it is defined

In this approach, the plural feature is semantically weak because it contributes nothing to the interpretation of the phrase it occurs in. The singular feature, on the other hand, is semantically strong because it contributes a presupposition of singleton (or atomic) reference.

The exclusive reading of plurals exemplified in (1b) is derived with the help of the principle of Maximize Presupposition originally proposed in Heim 1991 to account for the non-uniqueness inference of indefinite DPs. If there is a choice between two alternative morphemes that differ only in that one has more presuppositions than the other, this principle requires speakers to choose the morpheme that has the most presuppositions satisfied in the context. Given the semantics in (5), Maximize Presupposition predicts that the plural form in (1b) is interpreted as exclusive since if the atomic presupposition of the singular had been met, Maximize Presupposition would have mandated the use of the singular form. 
In order to account for the inclusive interpretation of plural forms in sentences such as (3a-c), Sauerland et al. weaken Maximize Presupposition as in (6):

(6) Maximize Presupposition applies to the scope of an existential if this strengthens the entire sentence.

Sauerland et al. treat indefinites as generalized quantifiers with existential force, and decompose no syntactically into an indefinite and negation. Presupposition maximization applied to the scope of the existential adds a condition that would make the entire utterance logically weaker when the existential occurs in a downward entailing environment. The generalization in (6) blocks this process, and thus predicts an inclusive reading for plural indefinites within the scope of negation and more generally, in downward entailing environments. There are, however, problems concerning the precise details of when and how Maximize Presupposition is suspended, for a discussion of which we refer the reader to Spector (2007: 267-271).

A different account is argued for in Spector 2007. Spector also posits two number features, a singular and a plural, but in this approach each has its own semantic contribution. The semantics of the singular feature imposes atomic reference while the semantics of the plural is inclusive. The exclusive plural interpretation of ( $1 \mathrm{~b})$ comes about as the result of a second-order scalar implicature denying the 'exactly one' reading of $(\mathrm{lb})^{2}$. For details and contrasts in predictions between Sauerland's position and Spector's with respect to bare plurals in non-monotonic and universally quantified contexts, see Spector 2007.

The analysis we develop here shares with these earlier approaches the insight that the competition between singular and plural forms drives their interpretation in a process that intertwines semantics and pragmatics. The crucial difference between these earlier approaches and ours is that we treat the singular as semantically weak and the plural as semantically strong. Krifka (1989) and Sauerland et al. (2005) use blocking to derive the interpretation of the semantically weak plural given the existence of a semantically strong singular, whereas we posit a semantically strong plural, and use blocking to derive the interpretation of the semantically weak singular. This reversal is worth striving for because it reconciles the semantics of number with Horn's division of pragmatic labor, an issue we turn to next.

2 Note that this implicature is independent of the suitability implicature that Cohen (2005) proposes to distinguish bare plurals from plurals with an overt indefinite determiner. 
Singulars and Plurals

\subsection{Reconciling number semantics with the Horn pattern}

Any account in which the singular feature makes a semantic contribution while the plural does not forces one to distinguish between semantic and morphological markedness. It has long been known that there is a strong tendency for languages that have a singular/plural contrast in nominals to morphologically mark plural forms and leave singular forms morphologically unmarked (Greenberg 1966; Corbett 2000). ${ }^{3}$ Such languages have a morpheme used in plural nominals but no special singular morpheme, and therefore plural forms are morphologically marked while singulars are not. But under a strong singular/weak plural view, it is the singular that makes a semantic contribution while the plural is semantically vacuous. Thus, in Sauerland et al. 2005 the singular is morphologically unmarked, but semantically marked (cf. 5a), while the plural is morphologically marked and semantically unmarked (cf. 5 b). ${ }^{4}$ It is, in fact, this very tension between semantic and morphological markedness that made the existence of inclusive plurals interesting in the first place. McCawley (1981) raises the question of how to reconcile the morphology and the semantics of number given the general tendency of language to pair morphologically unmarked forms with semantically unmarked meanings. The morphological asymmetry between singular and plural forms is also unexplained under the analysis in Spector 2007 because in that account both singular and plural features are semantically potent.

Following van Rooij (2004) and others, we call the fundamental connection between semantic and morphological markedness Horn's division of pragmatic labor or the Horn pattern, but note that this generalization has a long history that reaches back long before Horn's work. Citing structuralist and Prague school views on markedness, Horn (2001: 155) describes it as follows: “... one member of an opposed pair is literally MARKED (overtly signaled) while the other is UNMARKED (signaled via the absence of an overt signal). Semantically, the marked category is characterized by the presence of some property $\boldsymbol{P}$, while the corresponding unmarked category entails

3 Exceptions to this generalization exist, and are discussed in the literature. For instance, in some 'singulative' languages such as Welsh, a singular morpheme is used in instances where unmarked reference is to groups, or to unindividuated mass. Some instances of reversed markedness are addressed in de Swart \& Zwarts (2010). We will be concerned here with the typologically most frequent pattern, where the plural is morphologically marked, but the singular is not.

4 For further discussion of the special status of number within nominal $\phi$ features with respect to semantic and morphological markedness within the assumptions of Sauerland (2003) and Sauerland et al. (2005), see Sauerland (2008). 
nothing about the presence or absence of $\boldsymbol{P}$ but is used chiefly (although not exclusively) to indicate the absence of $\boldsymbol{P}$ (Jakobson 1939)".

Any strong singular/weak plural analysis involves an anti-Horn pattern because in such an approach the singular forms are assigned a strong semantics (requiring atomic reference, which plays the role of $\boldsymbol{P}$ above), while plural forms are given a weak interpretation, neutral with respect to whether values are chosen among atoms or sums. Recently, Bale, Gagnon \& Khanjian (in press) have explicitly defended the anti-Horn pattern for number, claiming that the empirical data are only reconcilable with a negative correlation between morphological and semantic markedness. A central goal of the present paper is to challenge the anti-Horn view, and achieve a reconciliation of the semantics and the morphology of number, formulated in A:

A. Plural forms should be semantically marked relative to singular forms so as to preserve the correspondence between morphological and semantic markedness seen elsewhere in language.

Analyses that are in line with the Horn pattern in the sense that they treat the plural feature as making a semantic contribution while treating the singular as semantically vacuous are called here weak singular/strong plural approaches. They are preferable on theoretical grounds to their competitors because they explain the asymmetry in number morphology in languages that have a plural but no singular morpheme and thus reconcile morphological and semantic markedness. Endowing the plural morpheme with a semantic contribution and deriving the interpretation of singular forms from the absence of the plural morpheme makes sense of the systematic morphological asymmetry between singular and plural forms. The existence of inclusive plural readings constitutes the main empirical challenge for the weak singular/strong plural approach. Before we address this problem and offer a solution, we present data from Hungarian that appears puzzling for a strong singular/weak plural account but not for a weak singular/strong plural view.

\subsection{Cross-linguistic challenges}

In this subsection we review two sets of facts that add further challenges to any account of number interpretation. The first comes from Hungarian, a language that displays a pattern of number marking that raises an empirical challenge to approaches that treat singular forms as requiring atomic reference. Just like English and other Indo-European languages, Hungarian has a singular/plural distinction: 
Singulars and Plurals

(7) a. Mari látott egy lovat.

[Hungarian]

Mari saw a horse.ACC

'Mari saw a horse.'

b. Mari látott lovakat.

Mari saw horse.PL.ACC

'Mari saw horses.'

There is no special morphology marking singular forms, while the plural feature is realized by the morpheme $-(a) k .^{5}(8 b)$ shows that in Hungarian, just like in English, verbs must agree with their subjects in number, and that $(a) k$ realizes the plural feature on verbs as well:

a. A gyerek elment.

the child leave.PAST

'The child left.'

b. A gyerekek elmentek / *elment.

the child.PL leave.PAST.PL / leave.PAST

'The children left.'

Hungarian is like English also in that plural nominals may have inclusive uses. In (9a) for instance, the addressee is expected to give a positive answer even if she saw a single horse, (9b) claims that Anna has not seen one or more horses, and (9c) asks the addressee to say something if she saw one or more horses. ${ }^{6}$

(9)
a. Láttál valaha lovakat?
see.PAST.II ever horse.PL.ACC
'Have you ever seen horses?'
b. Anna nem láttot lovakat.
Anna not see.PAST horse.PL.ACC
'Anna hasn't seen horses.'
c. Ha láttál valaha lovakat, szólj.
if see.PAST.II ever horse.PL.ACC say.IMP
'If you have ever seen horses, say so.'

5 The vowel $a$ is in parentheses here because in many phonological analyses it is treated as epenthetic. The quality of this vowel is determined by vowel harmony as well as by morphological considerations that are irrelevant for our purposes.

6 The contrast between inclusive and exclusive plurals in Hungarian is complicated by the fact that in this language bare nominals (whether singular or plural) can incorporate, an issue discussed at length in Farkas \& de Swart 2003. Incorporated singulars are number neutral, while incorporated plurals have sum reference. We will not be concerned with incorporated nominals in this paper, but only note that our proposals are compatible with the analysis of incorporation proposed by Farkas \& de Swart (2003). 
The problematic data concern DPs whose determiner entails reference to sums, including but not limited to cardinals bigger than one, exemplified in (10): ${ }^{7}$
a. három gyerek / *három gyerekek three child / three child.PL 'three children' many child / many child.PL 'many children'
b. sok gyerek / *sok gyerekek
c. mindenféle gyerek / *mindenféle gyerekek all.kind child / all.kind child.PL 'all kinds of children'
d. több gyerek / *több gyerekek more child / more child.PL 'more children'
e. egy pár gyerek / *egy pár gyerekek a couple child / a couple child.PL 'a couple of/some children'

As one can see from these examples, such DPs must be morphologically singular. Note that these cases involve not only cardinal numerals but other types of Ds as well. Therefore, no analysis specific to cardinals, such as the one proposed in Ionin \& Matushansky 2006, can cover all the relevant examples. That these DPs are semantically plural can be seen from the fact that they may occur as subjects of verbs like összegyülni 'to gather', as seen in (11a). The fact that they are not necessarily distributive, and therefore that they are, or at least, can be, referential is shown in (11b-d). ${ }^{8}$ The data are the same for all the D types exemplified in (9).
a. Sok gyerek gyúlt össze a téren.
many child gather.PAST PART the square.on
'Many children gathered in the square.'
b. Három gyerek felemelt egy zongorát.
three child lift.PAST a piano.ACC
'Three children lifted a piano.'

\footnotetext{
7 Hungarian is not the only language that displays this pattern of number marking, but it is sufficient to work out the data for one particular language to make the relevant theoretical point.

8 We are grateful to an anonymous reviewer for drawing our attention to the data in (11b-d).
} 
Singulars and Plurals
c. A három gyerek elérte a plafont. the three child reach.PAST the ceiling.ACC 'The three children reached the ceiling.'

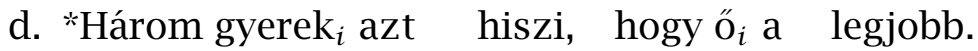 three child it.ACc believe that III the best 'Three children think that he $_{i}$ is the best'

Example (11b) is most naturally interpreted as involving a single lifting of a single piano in which three children participated together. (11c) can be interpreted as involving the reaching of the ceiling by one child helped along by her two teammates. In (11d) we see that just like in the English equivalent, * Three children think that he $_{i}$ is the best, these DPs cannot bind singular pronouns. Note that these properties distinguish the DPs in (10) and (11) from necessarily quantificational, non-referential DPs such as those headed by each/mindegyik in English and Hungarian respectively.

The data in (10) are compatible with Rullmann \& You's (2003) semantics of number, but their analysis of the Hungarian singular as number neutral associates exclusive sum reference with the plural morpheme, and therefore does not account for the inclusive interpretation of the plural in (9). The analyses in Sauerland et al. 2005 and Spector 2007 have no problem with the inclusive plural interpretation in (9) but the singular form of the DPs in (10) is problematic, given that the atomic reference semantics that the singular is crucially supposed to have is violated here.

Next, note that we cannot simply treat these forms as involving the presence of a $[\mathrm{Pl}]$ feature within the nominal that happens not to be realized on the head N. Such an analysis would predict that these DPs trigger plural verb agreement when in subject position, a prediction that is not borne out, as shown in (12):
a. Három gyerek elment / *elmentek three child leave.PAST / leave.PAST.PL 'Three children left.'
b. Mindenféle gyerek jelentkezett / *jelentkeztek all.kind child apply.PAST / apply.PAST.PL 'All kinds of children applied.'

Finally, note that the DPs in (9) are similar to plural DPs in that discourse pronouns referring back to them must be plural. If (13) is the continuation of (12a) and if the three children are to be the antecedent of the direct object 
pronoun, that pronoun must be plural.

(13) Mari nem látta őket / *ôt.

Mari not see.PAST III.PL.ACC / III.ACC

'Mari didn't see them.'

These observations show that the DPs in (10) are semantically plural in that they refer to sums but that morphologically, they are singular. This characterization accounts for the data under the assumption that SubjectVerb agreement is sensitive to the morphological feature of the DP, while the form of a discourse pronoun is sensitive to the semantics of its antecedent (see Farkas \& Zec 1995 for discussion). The morphology explains the intrasentential agreement pattern these DPs trigger while their semantics explains the form of the discourse pronouns for which they serve as antecedents.

We see then that in Hungarian, singular forms must be used in certain cases of sum reference, a situation that is problematic for any strong singular view. The challenge raised by the Hungarian data reviewed here is formulated in B.

B. There are languages with a morphological singular/plural distinction in nominals, where singular forms may have sum reference in case sum reference is entailed by the determiner.

The account of the contrast between English and Hungarian we offer in Section 4 below differs in empirical coverage from that found in Sauerland et al. 2005 and Rullmann \& You 2003 in that we capture the similarities between the two languages when it comes to the interpretation of ordinary plural forms in $(7,8,10)$ as well as the differences between them when it comes to the DP types exemplified in (9).

The second cross-linguistic empirical problem we consider is raised by languages such as Mandarin Chinese that do not have a morphological contrast between singular and plural forms. Nominals unmarked for number in such languages get a number neutral interpretation, as emphasised by Krifka (1995), on the basis of examples such as (14):

(14) Wò kànjiàn xióng le.

[Mandarin Chinese]

I see bear ASP

'I saw a bear/some bears.'

The empirical generalization we draw from contrasting the interpretation of non-plural forms in English-type languages and Chinese type languages is 
Singulars and Plurals

formulated in C.

C. In languages which lack morphological number marking on nominals, unmarked forms are number neutral.

We capture this generalization below but will not work out the semantics of Chinese nominals since we focus here on languages that have a morphological number distinction. Our approach to these languages is compatible with Rullmann \& You's semantics of Mandarin.

We have seen in this section that the naïve (and attractive) view of number interpretation we started with, according to which singular nominals refer to atoms and plural ones refer to sums, faces two stumbling blocks: (i) the existence of cases in which plural nominals are interpreted inclusively; (ii) the number marking system in languages like Hungarian, where certain singular nominals must receive a non-atomic interpretation. Retreating to a view according to which the singular is semantically potent while the plural is semantically empty runs against the Horn pattern of markedness, and has difficulty with the Hungarian data as well. In the remainder of this paper, we work out an account of number interpretation which:

i. accounts for the existence of the inclusive as well as the exclusive interpretation of plurals;

ii. respects the Horn pattern and is in line with the morphological markedness facts (generalization A);

iii. predicts when inclusive interpretations are possible (1b vs. 3 and $7 \mathrm{~b}$ vs. 9);

iv. predicts the possibility of certain singular forms referring to sums in languages like Hungarian (generalization B, examples 10-13);

v. is compatible with the number neutral interpretation of nominals in languages that do not have a morphological mark for plurals, such as Mandarin Chinese (generalization C, example 14).

We focus here on the semantics of number interpretation on nominals in regular argument position (cf. footnote 1), and do not discuss issues concerning the feature $[\mathrm{Pl}]$ when it occurs as an agreement feature on verbs and VPs for instance. We concentrate on N-headed nominals, and leave detailed discussion of pronouns and coordinate DPs for future work. 
Farkas and de Swart

\section{The semantics of singular and plural nominals}

In this section we give our account of the interpretation of the plural feature and its associated morpheme in the languages under consideration and derive the interpretation of singular forms based on it. We start from what we consider the null hypothesis, according to which, in languages with a binary number distinction, there is a single, privative morphological feature [Pl] in nominals and no singular feature. We assume that this feature is generated in NumP, a node that is dominated by DP. We give the feature [PI] a polysemous semantics and derive the restriction of singular nominals (i.e., nominals that lack the feature $[\mathrm{Pl}]$ ) to atomic reference under bidirectional optimization. The bidirectional OT model we use is based on Mattausch 2005, 2007, a set-up that captures the harmonization of unmarked forms with unmarked meanings, and of marked forms with marked meanings. ${ }^{9}$

\subsection{Bi-directional optimization over form-meaning pairs}

Our analysis is cast in the framework of Optimality Theory (OT), a theory that defines well-formedness in terms of optimization over a set of output candidates for a particular input. OT syntax, for instance, defines grammaticality as the optimal form that conveys a particular meaning, and thus represents the speaker orientation (production). OT semantics picks the optimal interpretation of a given form as the meaning construed by the hearer for that form (comprehension). Bidirectional OT deals with the syntax-semantics interface by combining the two directions in an optimization process over form-meaning pairs (Hendriks, de Hoop, de Swart \& Zwarts 2010). This framework is appropriate for the problem at hand because it allows us to treat the interpretation of singular and plural nominals in tandem, as a matter of competition between the two forms.

As was made clear in the previous section, we treat as fundamental to the enterprise the fact that plural forms are morphologically marked and singular forms are not. Bidirectional OT is particularly useful to us because Mattausch $(2005,2007)$ has already worked out in this framework an abstract way of modeling the association of forms and meanings as an optimal communication strategy that captures the Horn pattern. His proposal

9 Mattausch's work goes back to ideas developed by Jäger (2003) and Blutner (1998, 2000, 2004). For a slightly different bidirectional OT set-up, see Beaver 2002. For a comparison of different bidirectional OT models, see Beaver \& Lee 2004. 
Singulars and Plurals

can be applied to our problem in a straightforward way.

The gist of Mattausch's system is the following. Suppose there are two forms, one overtly marked $(m)$, the other unmarked $(u)$ and suppose there are two meanings, an unmarked (more frequent, or simpler) meaning $\alpha$ and a marked (less frequent, or more complex) meaning $\beta$. Their combination leads to four possible form-meaning pairs: $\langle u, \alpha\rangle,\langle m, \alpha\rangle,\langle u, \beta\rangle,\langle m, \beta\rangle$. How do we determine which pairs are the optimal, most harmonic ones?

As a starting point, Mattausch posits four bias constraints, one for each of the possible form-meaning pairings:

(15) Bias constraints

* $m, \alpha$ : the (marked) form $m$ is not related to the (unmarked) meaning $\alpha$.

${ }^{*} m, \beta$ : the (marked) form $m$ is not related to the (marked) meaning $\beta$.

$* u, \alpha$ : the (unmarked) form $u$ is not related to the (unmarked) meaning $\alpha$.

* $u, \beta$ : the (unmarked) form $u$ is not related to the (marked) meaning $\beta$.

These constraints penalize all possible form-meaning combinations. They become operative only because they are differentially ranked relative to a general markedness constraint, "MARK, a constraint that penalizes the use of the marked form. This constraint models a notion of economy that prefers simpler forms over more complex ones.

All constraints are soft, but the ease with which they can be violated depends on their relative strength. The ranking of *MARK with respect to the bias constraints reflects the balance of economy considerations relative to faithful correspondence relations between forms and meanings in the process of optimal communication. Mattausch derives the ranking of the bias constraints relative to the markedness constraint from iterated learning over several generations in a computational learning model based on frequency distributions (cf. Kirby \& Hurford 1997). Comparisons of forms and meanings trigger the promotion or demotion of constraints. If the marked meaning is less frequent, iterated learning over several generations with the four bias constraints leads to a stochastic OT grammar in which the ranking of the bias constraints mirrors the frequency distribution of the meanings $\alpha$ and $\beta$.

The central idea we take over from Mattausch's work is that the relative ordering of the bias constraints and the markedness constraint is such as to result in an absolute preference for the association of the unmarked meaning 
with the unmarked form and the association of marked meaning with the marked form thereby capturing Horn's division of pragmatic labor. The universal constraint ranking Mattausch derives is given in (16):

$$
\{* u, \beta ; * m, \alpha\} \gg * \text { MARK } \gg\{* u, \alpha ; * m, \beta\} .
$$

Marked forms always violate *MARK, so under the ranking in (16), they only appear with the marked meaning $\beta$. Mattausch $(2005,2007)$ derives the emergence of Horn's division of pragmatic labor as the optimal communication strategy that arises under evolutionary pressure.

\subsection{Morphological and semantic markedness in the domain of number}

Before we can apply Mattausch's abstract model to the interpretation of singular and plural nominals, we have to establish which forms and which meanings correspond to $u, m, \alpha$ and $\beta$ in the domain of number, and we have to establish what the relevant markedness constraint is.

Concerning formal markedness, recall that we are concerned with the typologically frequent pattern in which the plural is morphologically marked, and the singular remains unmarked. Because of this asymmetry, the singular is the unmarked form $u$, and the plural is the marked form $m$. On this point the literature is in agreement: see Sauerland 2008 and Bale et al. (in press) for recent discussion. We differ from previous approaches, however, in adopting the null hypothesis and taking plural morphology to mark the presence of the privative feature [Pl], and not positing a singular feature or a null singular morpheme.

Establishing semantic markedness is a more delicate matter because there are several distinct parameters along which it can be defined, besides frequency. We mention here some major contenders. Denotational markedness involves the subset relation between the denotation of an item $i$ and that of an item i'. For instance, the lexical item $\mathrm{dog}$ is denotationally unmarked relative to the lexical item bitch. Conceptual markedness concerns the nature of the denotation of two items: the denotation of the unmarked item $i$ is conceptually simpler than the denotation of the marked item i'. In temporal semantics, for instance, the present is perceived as conceptually less marked than the past and the future since the latter two are defined in terms of the former (Lakoff 2000: 44). Finally, we distinguish a third type of semantic markedness, semantic complexity according to which an item $i$ is less marked than an item $i$ ' iff $i$ ' is associated with a semantic requirement that is lacking 
Singulars and Plurals

in $i$. For example, the definite article is semantically more complex than the indefinite one under analyses where the definite article is associated with a uniqueness requirement while the indefinite article is neutral in this respect (see Heim 1991 and Farkas 2006).

In discussions of semantic markedness in the domain of number, the notion of denotational markedness has dominated. As we have seen already, Sauerland et al. (2005) take the plural to denote within the entire domain of the nominal $(=* \mathrm{~N}$, cf. Figure 1 above) while Bale et al. (in press) assign the plural feature an augmentative semantics, which takes the join of all atoms and sums in the semi-lattice of $\mathrm{N}$. As a result, the denotation of the singular (which has to have atomic reference) is a strict subset of the denotation of the plural in both proposals. The same is true for the account in Spector 2007. Approaches which rely on denotational markedness alone then lead to an anti-Horn analysis. However, this is not the only way one can go in relating number interpretation to the Horn pattern.

Our analysis of number is grounded in a notion of markedness in terms of semantic complexity. No singular feature is posited for a singular nominal, and no inherent number semantics is assigned to this form. Plural nominals are assumed to involve an overt plural feature [Pl] realized by a plural morpheme whose semantic contribution concerns the atom/sum distinction. If a singular nominal is not inherently associated with any number semantics while a plural nominal comes with such a constraint, the singular form qualifies as semantically unmarked relative to the plural with respect to semantic complexity.

In addition, in terms of conceptual complexity, we take atomic reference to be less marked than sum reference. We follow Link (1983) in taking the domain of interpretation from which variables are assigned values to consist of atoms and sums, where the latter are built from the former by means of the join operation $\oplus$. Given that atoms may exist independently of sums, but not the other way around, a nominal that denotes within the domain of sums is conceptually more marked than one that denotes within the domain of atoms only.

Support for this conceptual markedness view is found in psychological research that points to the special nature of sum reference. Recent psychological research suggests that non-human primates and children under two represent small sets of objects as object-files, and do not establish a singular-plural distinction based on atoms vs. sums (Hauser, Carey \& Hauser 2000, Feigenson, Carey \& Hauser 2002, Feigenson \& Carey 2003, 2005). The 
evidence comes from a variety of non-linguistic tasks. ${ }^{10}$ Wood, Kouider \& Carey (2004) and Kouider, Halberda, Wood \& Carey (2006) assume that by the time children learn the meanings of linguistic markers for the singular-plural distinction, they must have distinguished between singletons and sets (or sums, in our terms). They do indeed find that children over two who have started to produce the plural marker understand that it signals reference to multiple objects. ${ }^{11}$ Whereas representations of individual objects and object arrays are available from ten months onward, the representation of multiple objects as sums is paired up with the acquisition of linguistic markers of plurality (around 24 months). The psycholinguistic evidence supports the view that sum reference is conceptually marked as opposed to reference to atoms.

In our view, the interpretation of nominal number concerns restricting the domain from which witnesses of a nominal can be chosen in terms of the atom/sum distinction. The conceptually marked reference is one that includes sums, i.e., one that allows possible sum witnesses. Allowing sums within the domain of reference is then the crucial markedness parameter when it comes to number interpretation in the languages under consideration. Consequently, the denotational space of nominals is divided into two subdomains, one that includes sums and one that excludes them. Nominals that refer in the latter domain have exclusive atom reference, while nominals that refer within the former have sum reference. Next, note that there are two ways in which a nominal can have sum reference: (i) its reference may be restricted to sums (excluding atoms), a case we call exclusive sum reference, and (ii) its reference may include sums but not exclude atoms, a case we call inclusive sum reference. Thus, the formally marked plural form may fulfil

10 For example, infants watch while sets of crackers are placed into two different buckets. When encouraged to crawl to one of the buckets, infants reliably choose the bucket with more crackers with numbers up to three. When one set of crackers exceeds three (in four vs. two, six vs. three or even four vs. one comparisons), infants up till 20 months are at chance. All they would have to do to succeed on a one vs. four comparison is to represent one as a singular individual and four as a plurality, but they fail to do so, and do not show a preference for the bucket containing more crackers. The three-item limit is expected when infants' representation is object-based, as the object-file system is assumed to be subject to the working memory limit of three to four items.

11 The experiments use a preferential looking paradigm, and tested sensitivity to number expressed on the verb (is/are), on the noun (using nonsense words, e.g. the blicket/the blickets) and with quantifiers (a blocket/some blickets). The results suggest that learning the force of number marking on linguistic expressions strongly correlates with the conceptual distinction between sets (sums) and individuals (atoms). 
Singulars and Plurals

the requirement of being associated with the conceptually marked number interpretation by being associated with either inclusive or with exclusive sum reference. In the latter case all witnesses must be sums while in the former case some witnesses must be sums. The formally unmarked singular form is conceptually unmarked when its denotation excludes sum reference, i.e., when it denotes exclusively in the realm of atoms.

When it comes to denotational markedness, matters are complicated because the domain of atoms is, of course, a subset of the domain of atoms and sums. Note, however, that in our account, singular nominals do not have a number feature of their own and thus do not involve inherent number semantics. Plural forms on the other hand are treated as having a number feature whose semantics forces them to include sums within their denotation and thus a plural form cannot denote exclusively in the realm of atoms. We suggest that because of the competition with plural forms, the denotation of singular nominals ends up being restricted to the complement of the denotation of plurals, i.e., singular nominals end up being interpreted as denoting in the exclusive atom realm. More specifically, the account we propose involves the formally and conceptually marked plural form blocking the formally and conceptually unmarked singular form from being interpreted as having sums within its domain. When the competition between the singular and the plural is inoperative, however, singular forms are number neutral, and can, in principle, denote in any subdomain of the lattice. Hungarian sum denoting singulars are a case in point. What is impossible, according to our account, is for a plural form to have exclusive atomic reference, a situation that is indeed unattested as far as we know.

In the next subsection we make these proposals concrete by implementing Mattausch's abstract system of the pairing of form and meaning in the domain of number. The core operative concept for number interpretation in our system is conceptual markedness according to which atomic reference is the unmarked meaning $\alpha$, whereas sum reference (whether inclusive or exclusive) is the marked meaning $\beta$.

\subsection{Distribution of atomic/sum reference over singular/plural nominals}

The forms we are dealing with in the bidirectional optimization process are morphologically singular and plural nominals, which we denote by $s g$ and $p l$. $S g$ here is short for a DP that has no number feature in its NumP, while $p l$ is short for a nominal that has the feature $[\mathrm{Pl}]$ in NumP. The interpretations 
associated with these forms are atomic reference and inclusive or exclusive sum reference respectively, which we denote by at and i/e sum. The bias constraints for number are given in (17):

(17) Bias constraints for number:

"pl, at: a plural nominal does not have atomic reference.

"pl, i/e sum: a plural nominal does not have inclusive/exclusive sum reference.

*sg, at: a singular nominal does not have atomic reference.

"sg, i/e sum: a singular form does not have inclusive/exclusive sum reference.

The markedness constraint on forms is *FUNCTN, the constraint proposed by de Swart \& Zwarts $(2008,2009,2010)$ as the central economy constraint in the nominal domain:

*FUNCTN: avoid functional structure in the nominal domain

*FUNCTN prefers 'bare' nominals without articles, number morphology, classifiers, etc. over nominals involving the functional features or projections that host these expressions. The elaborate structures we find in the nominal domain support the view that *FUNCTN is a soft, violable constraint that can be overruled by faithfulness constraints driving the expression of sum reference, discourse referentiality, definiteness, etc. (cf. de Swart \& Zwarts 2008, Hendriks et al. 2010: chapter 7). However, its influence is pervasive, even in languages in which such faithfulness constraints are ranked high, as argued by de Swart \& Zwarts (2009) in relation to a range of bare nominal constructions in Germanic and Romance languages.

The crucial ordering that emerges under the assumption that i/e sum reference is semantically more marked than atomic reference is in (19):

(19) The Horn pattern for number

$$
\{* \text { sg, i/e sum; *pl, at }\} \gg * \text { FUNCTN } \gg\{* p l, i / e \text { sum; *sg, at }\}
$$

The ranking in (19) captures the insight that nominals marked with the feature [Pl] must include sums within their domain of reference, and that the interpretation of a singular form (when in competition with a plural) is atomic reference. In line with Horn's division of pragmatic labor, the ranking in (19) pairs up marked plural forms with marked sum reference meanings, and unmarked singular forms with unmarked atomic meanings. The optimization over form-meaning pairs under this ranking is spelled out in the bidirectional 
Singulars and Plurals

\begin{tabular}{|c|c|c|c|c|c|}
\hline & ${ }^{*} s g, i / e$ sum & *pl, at & *FUNCTN & *pl, i/e sum & ${ }^{*} s g$, at \\
\hline$\langle s g, a t\rangle$ & & & & & $*$ \\
\hline$\langle s g$, at $\cup$ sum $\rangle$ & $*$ & & & & \\
\hline$\langle s g$, sum $\rangle$ & $*$ & & & & \\
\hline$\langle p l, a t\rangle$ & & $*$ & $*$ & & \\
\hline$\langle p l, a t \cup s u m\rangle$ & & & $*$ & $*$ & \\
\hline$\langle p l$, sum $\rangle$ & & & $*$ & $*$ & \\
\hline
\end{tabular}

Tableau 1 Optimization over singular/plural form-meaning pairs

Tableau1, where singular and plural forms are paired up with their respective domain of interpretation in the lattice.

All possible form-meaning combinations are listed in the first column, and constitute the input to the bidirectional optimization process. The interpretations that particular forms are paired up with restrict the possible witnesses of the nominal. Atomic reference, represented as at, limits possible witnesses to atoms only. Exclusive sum reference, represented as sum, limits possible witnesses to sums only. Inclusive sum reference, represented as at $\cup$ sum, allows witnesses to be chosen both from the domain of atoms and that of sums.

The four bias constraints, plus the markedness constraint *FUNCTN are ranked across the top, where the left-right order reflects a decreasing order of strength, and follows the ranking in (19). The two bias constraints *sg, i/e sum and *pl, at are ranked above the markedness constraint *FUNCTN, but their mutual order is irrelevant, which is reflected in the dotted line between the two columns. Similarly, (19) requires the two constraints *pl, i/e sum and *sg, at to be both ranked below *FUNCTN, but their mutual order is irrelevant, as marked by the dotted line.

Because of the set-up with the bias constraints, all form-meaning combinations incur one or more violations, marked by an asterisk $*$ in the relevant cell. The schema in (19) ranks the bias constraints penalizing the combination of singular forms with (inclusive or exclusive) sum reference and the combination of plural forms with atomic reference above the markedness constraint *FUNCTN, which is what drives the optimization over form-meaning pairs in Tableau 1. The constraints mitigating against the combination of plural forms with (inclusive or exclusive) sum reference, or the combination of singular 
forms with atomic reference are ranked below *FUNCTN, and are de facto inactive in the optimization process. ${ }^{12}$

Tableau 1 shows that we assign the (unmarked) singular form the (unmarked) meaning of atomic reference under strong bidirectional optimization, because $\langle s g$, at $\rangle$ constitutes a bidirectionally optimal pair (\&): there is no better form to convey atomic reference, and there is no better meaning to associate with a singular form. The expression of sum reference calls for the use of a plural form. Both sum and at $\cup$ sum qualify as sum reference, so plural forms have exclusive or inclusive sum reference. Accordingly, both $\langle p l$, sum $\rangle$ and $\langle p l$, at $\cup$ sum $\rangle$ qualify as bidirectionally optimal pairs (\$). Crucially, however, a plural form cannot be used in case sums are not part of the meaning to be expressed, because $\langle p l$, at $\rangle$ is suboptimal. In line with Horn's division of pragmatic labor then, unmarked forms pair up with unmarked meanings, and marked forms pair up with marked meanings. Given this analysis, singular nominals have exclusive atomic reference when in competition with the plural, while plural nominals have (inclusive or exclusive) sum reference. ${ }^{13}$

We are proposing here a weak singular/strong plural account in which plurals are formally marked with a feature that is interpreted in compositional semantics, as spelled out in (20), while singular nominals have no explicit number feature and are restricted to atomic reference only as a result of the competition with the plural form. We capture this asymmetry by assuming that the interpretation of the feature [Pl] is as given in (20), where ${ }^{*} \mathrm{P}$ is the number neutral property denoted by the head noun and its complement (cf. Section 1.2 above). For any given occurrence of a plural form, either (20a) or

12 Technically, either the set of four bias constraints or the combination of *FUNCTN with the bias constraints ranked above it (i.e. *sg, i/e sum and "pl/at) is sufficient to obtain three bidirectionally optimal pairs in the ordinal Tableau 1 . That is, leaving out either *pl, i/e sum and *sg, at or *FuNCTN would not change the outcome of the optimization process. However, in Mattausch's system, we need a markedness constraint in the learning system in order to derive a $100 \%$ form-meaning distribution in the stochastic grammar. Note also that *FUNCTN plays a key role in the unidirectional optimization in Section 4.

13 The crucial difference between $\lambda x[x \in \operatorname{Sum} \cup$ Atom $\& * \mathrm{P}(x)]$ and $\lambda x * \mathrm{P}(x)$ is precisely the fact that the former is semantically plural, necessitating the possibility of sum reference while the latter is number neutral and thus truly insensitive to the atom/sum divide. We have seen in examples (4a-b) that the plural is indeed not insensitive to the atom/sum divide, and will work out in section 3.3 an analysis of choice of form that brings out the relevance of sum reference for plurals. 
Singulars and Plurals

(2ob) holds:
a. $\llbracket \mathrm{Pl} \rrbracket=\lambda x \lambda * \mathrm{P}[x \in \mathrm{Sum} \cup \operatorname{ATOM} \& * \mathrm{P}(x)]$
b. $\llbracket \mathrm{Pl} \rrbracket=\lambda x \lambda * \mathrm{P}[x \in \mathrm{SUM} \& * \mathrm{P}(x)]$

This interpretation ensures that the denotational space of plural nominals will always include sums, whether inclusively, as in (20a), or exclusively, as in (2ob). It is this property that makes the plural forms marked relative to singulars, in terms of Horn's characterization of markedness in Section 1. Crucially, the two interpretations in (20) are semantically related since (2ob) asymmetrically entails (20a): whenever a witness meets the condition in (2ob), it also meets the condition in (20a) but not the other way around. This, therefore, is a case of polysemy rather than one of arbitrary ambiguity.

The semantics in (20) leads to the truth conditions of sentences like (1b) and a simplified version of (3a) (repeated here as 21a and 22a) as in (21b) and (22b), respectively:

a. Mary saw horses

[exclusive plural]

b. $\exists x:\left[x \in \operatorname{Sum} \&{ }^{*} \operatorname{HoRSE}(x)\right][\operatorname{SEE}(m, x)]^{14}$

a. Have you seen horses?

[inclusive plural]

b. ? $[\exists x:[x \in \operatorname{Sum} \cup \operatorname{Atom} \& * \operatorname{HorSE}(x)][\operatorname{SeE}(\operatorname{addressee,} x)]]$

Thus, nominals with the feature $[\mathrm{Pl}]$ are incompatible with the conceptually unmarked meaning, namely exclusive atomic reference. The reference of such forms is restricted by the contribution of the feature [Pl] to a domain that includes sums either to the exclusion of atoms or not. In Section 3 we exploit the entailment relation between these two senses to account for the pragmatic factors that play a role in choosing one sense over the other.

Since our analysis appeals to the feature [Pl] but has not implicated particular determiners, it carries over straightforwardly to the definite plural in (23a):

a. Mary touched the horses.

b. $\exists ! x:\left[x \in \operatorname{Sum} \&{ }^{*} \operatorname{HoRSE}(x)\right][\operatorname{Touch}(m, x)]$

We assume that in English the definite article, as well as 'definite' possessive determiners such as your horse/your horses have no number restrictions of

14 We use here and below First Order Predicate Logic formulas with restricted quantification. We put square brackets around the Restrictor and the Nuclear Scope, and use capitals to distinguish logical predicate constants from their natural language counterparts. We disregard matters that are not directly relevant to us, such as tense interpretation. 
their own since they combine with both singular and plural nominals. In the case of the latter, the feature [Pl] is present in the NumP and brings its contribution to the semantic interpretation of the DP. Given that we assume NumP to be dominated by DP, we also assume that the feature [Pl], like other agreement features, percolates to the DP in order to trigger plural agreement outside the DP, as in the case of Subject-Verb agreement.

Our account leads us to expect inclusive plural possessive or definite DPs alongside inclusive plural indefinites. Example (24) shows that this expectation is met:

(24) [Instruction for parents picking up their kids from day care after an outing in different groups]: If your children are back late, you have to wait.

Your children in (24) is interpreted inclusively, for the instruction is assumed to be relevant both to parents with a single child and to parents with more than one child in day care. The inclusive interpretation of the plural possessive in (24) is parallel to the inclusive interpretation of indefinite plurals in the restrictor of conditionals, exemplified in (3b) and repeated here as (25):

(25) If you have ever seen horses in this meadow you should call us.

The plural definite in (23a), on the other hand, gets an exclusive plural interpretation on a par with that of the bare plural in (21a).

Singular nominals do not involve a singular feature in NumP and therefore they do not have an inherent denotation restriction concerning the atom/sum divide imposed by any of their subparts. The denotation of the singular nominal horse is the number neutral property $\lambda \mathrm{x}\left[{ }^{*} \operatorname{HORSE}(\mathrm{x})\right]$, an interpretation that is insensitive to the atom/sum divide. Crucially, however, we assume that the interpretation of count nominals in argument position in languages with morphological number has to involve information concerning the atomic vs. sum nature of their referent. In other words, a nominal that introduces a discourse referent (i.e, a nominal of type $e$ ) in these languages has to be interpreted as giving information concerning the atom/sum nature of its possible witnesses.

Under standard assumptions in Discourse Representation Theory, discourse referents are introduced at the point when the D combines with its sister(cf. Kamp \& Reyle 1993; Kamp \& van Eijck 1996). Because number restrictions target the possible values of discourse referents, we assume that it is at this point that the presence of a number restriction becomes 
Singulars and Plurals

relevant. In the case of plural nominals, the interpretation of the feature [Pl] in NumP contributes the required number restriction. In the case of singular nominals, however, there is no explicit number feature that can contribute the required number information. When a singular nominal combines with a determiner that itself is not specified for number, such as the definite article the, number specification is contributed via the optimization mechanism given above. Such a singular DP denotes exclusively within the set of atoms because allowing reference to sums has to involve the presence of $[\mathrm{Pl}]$ in NumP according to Tableau 1. Thus, at the point when a number neutral D such as the combines with a morphologically singular sister nominal that has no inherent number specification either, such as horse, the system of constraints in Tableau 1 enriches the interpretation of the DP with the constraint $\mathrm{x} \in$ Aтом imposing exclusive atomic reference on the DP because this is the optimal number interpretation for a DP that is not marked with the feature [Pl]. The compositional semantics yields no number requirement on its own but in the absence of plural morphology, the DP will be interpreted as having atomic reference. ${ }^{15}$

Note that our account of the interpretation of singular DPs is similar in spirit to Krifka's account of number interpretation for plural nominals. For Krifka, singular DPs are marked for atomic reference and plural nominals denote in the complement of the singular forms. For us, plural nominals are marked for including sums in their reference domain, and singular DPs, when in competition with plurals, denote in the complement of the plural form, i.e., they are interpreted as having exclusive atom reference.

The truth conditions of sentences like (1a), repeated here as (26a), involving a singular form in competition with a plural one, are then as given in (26b).

a. Mary saw a horse.

b. $\exists x:[x \in \operatorname{ATOM} \& * \operatorname{HoRSE}(x)][\operatorname{SAw}(m, x)]$

The condition $\mathrm{x} \in \mathrm{ATOM}$ is present because nothing in the inherent semantics of some horse specifies that sum reference is a possibility, and therefore the

15 We are assuming here that the OT system works hand in hand with composition rather than applying at a particular point in the derivation of the interpretation of an expression. The type of enrichment we use here is different from the 'pragmatic enrichment' proposed most recently in Chierchia 2004, 2006; Chierchia, Fox \& Spector 2008, which relies on a covert exhaustification operator. Note also that our account of the singular/plural contrast is different from that assumed in Chierchia 2004, 2006; Chierchia et al. 2008 in that in our account singular forms do not involve a feature that imposes atomic reference. 
restriction to atomic reference is imposed by the constraints in Tableau 1. This condition then is not contributed by the presence of a particular piece of morphology in (26a) but rather, by the absence of the feature [PI]. ${ }^{16}$

The analysis extends in a straightforward way to the definite singular nominal in (27):

(27) a. Mary touched the horse.

b. $\exists ! x:\left[x \in \operatorname{ATOM} \&{ }^{*} \operatorname{HoRSE}(x)\right][\operatorname{Touch}(m, x)]$

Note that the definite article requires uniqueness, whereas the indefinite article just contributes existential quantification. We exploit this difference in Section 3.2 below.

The account we proposed above allows explicit semantic information to be contributed by an unmarked form that has no inherent semantics on the basis of the competition with a marked form with a specific semantics. The bidirectional OT system spells out the details of a blocking account in the spirit of Krifka (1989) and Sauerland et al. (2005) with the important difference that in our system the existence of the semantically and morphologically marked plural form affects the interpretation of the semantically and morphologically unmarked singular form rather than the reverse

The most important challenge for a weak singular/strong plural view is the existence of inclusive readings of plural forms. The polysemous semantics of plural nominals that we adopted in (20) as the outcome of the bidirectional optimization process meets this challenge as it leaves room for both inclusive and exclusive sum reference. Following the spirit though not the letter of Sauerland et al. (2005) and Spector (2007), we rely on pragmatics to determine the choice between these two senses in context and give, in the next section, a pragmatic account of the contrast between ( $1 \mathrm{~b}),(3 \mathrm{a}-\mathrm{c})$ and (4a, b).

16 We assume here that the atom condition is part of the semantics of the relevant DPs. Alternatively, one could treat it as an implicature whose generation would rely on the constraints in Tableau 1. Under both views singular DPs are taken to denote within the realm of atoms because languages that have a plural form have to use it, other things being equal, in case sums are among the possible referents of the DP and thus, the existence of the plural blocks the singular from being interpreted as having sum reference. The implicature analysis sketched here differs sharply from the use of implicature in Spector (2007) summarized in Section 1.2 above. 
Singulars and Plurals

\section{The pragmatics of the plural}

So far we have worked out a weak singular/strong plural analysis of number interpretation in which plural nominals are interpretable as having either inclusive or exclusive sum reference. In Section 1 we saw that both interpretations are indeed available for such nominals. We also saw, however, that the choice between them is not free: exclusive sum reference is the rule in upward entailing environments, as exemplified in (21) and (23), whereas inclusive readings are typically found in downward entailing environments such as the scope of negation, in the restrictor of a universal or the antecedent of a conditional, as well as in questions (cf. 22, 24 and 25). In section 3.1 we turn to the problem of explaining this contrast. We suggest that a crucial factor regulating the choice between the two senses of the plural is the independently motivated S(trongest) M(eaning) H(ypothesis), a pragmatic principle that can be constrained under contextual pressure. We discuss, in Section 3.2, the predictions this hypothesis makes for the interpretation of plural forms in quantificational contexts. The interpretation of singular and plural forms comes closest in environments where the plural is interpreted inclusively because in such cases both forms are compatible with atomic witnesses. In Section 3.3 we investigate factors that regulate the choice between singular and plural forms in downward entailing environments and questions, environments where a plural is most likely to receive an inclusive interpretation.

\subsection{Strongest meaning hypothesis for number}

If plurals can have either an inclusive or an exclusive interpretation, along the lines of (20), the question of how one chooses between these two possibilities arises immediately. We have noted above that the exclusive interpretation asymmetrically entails the inclusive one. This, we claim, makes the choice between the two interpretations sensitive to the Strongest Meaning Hypothesis. In this section we make this connection explicit and discuss its predictions.

Recall that Dalrymple, Kanazawa, Kim, Mchombo \& Peters (1998) propose the Strongest Meaning Hypothesis (SMH) to account for the contextual choice between a range of interpretations for reciprocals. Winter (2001) extends the principle to instances of Boolean conjunction and quantification. Zwarts (2004) exploits the SMH as part of his interpretation procedure for the preposition round. We exploit here the same idea in claiming that the SMH 
is one of the factors that govern the choice between the inclusive and the exclusive sum interpretation of plural nominals.

The Strongest Meaning Hypothesis applies when an expression is assigned a set of interpretations ordered by entailment and chooses the strongest element of this set that is compatible with the context. ${ }^{17}$ The two senses of the feature [Pl] in our account, given in (20), are ordered by (truth-conditional) strength: an existentially closed proposition involving the exclusive sense asymmetrically entails the same proposition involving the inclusive sense. Because of this relationship the choice between interpretations of the [Pl] falls under the jurisdiction of SMH. Our hypothesis is formulated as SMH_PL (the Strongest Meaning Hypothesis for Plurals):

SMH_PL: the Strongest Meaning Hypothesis for Plurals: for a sentence involving a plural nominal, prefer that interpretation of [Pl] which leads to the stronger overall interpretation for the sentence as a whole, unless this interpretation conflicts with the context of utterance.

In upward entailing environments exemplified in (21a) and (23a), the sentence under the exclusive interpretation of the plural entails the sentence under the inclusive interpretation, and therefore the SMH_PL favors the exclusive interpretation of horses and the horses over the inclusive one. In other words, the interpretation that Mary saw 'more than one' horse is stronger than the claim that Mary saw 'one or more' horses, and therefore the SMH_PL favors the exclusive plural interpretation in (21b). Similarly, the statement that Mary touched the maximal sum of horses in the context entails the proposition that Mary touched the maximal set of one or more horses, so the SMH_PL also favours the exclusive plural interpretation in (23b).

In downward entailing environments on the other hand, the SMH_PL leads to the inclusive interpretation because of scale reversal under monotonicity reversal (see Fauconnier 1979 and much subsequent work). ${ }^{18}$ The weaker, inclusive reading of the plural in such contexts leads to a stronger claim for the sentence as a whole. This indeed is the case for (3a-c, 22, 24, 25). With respect to (3c), for instance, the proposition that Mary never saw 'one or more' horses (inclusive plural) entails the proposition that Mary never saw

17 Note that Sauerland et al. (2005) also makes reference to strength when suspending Maximize Presupposition in cases where disobeying this principle would lead to a stronger overall claim, cf. (6) in Section 1.2.

18 Whenever relevant, the notion of downward entailment can be refined to 'Strawson entailment', e.g. in conditionals (cf. von Fintel 1999). 
Singulars and Plurals

more than one horse (exclusive plural). Given that the inclusive interpretation of the plural in (3c) leads to a stronger claim for the negative sentence than the exclusive interpretation, the former interpretation is preferred under the SMH_PL. We assume here that the SMH_PL is relevant to bringing about the inclusive interpretation of plurals in questions as well, though the details of how to compute the strength of questions must remain an open issue for the time being, despite the fact that the affinity between downward entailing contexts and questions has been noted for a long time. ${ }^{19}$ Other things being equal then, the SMH_PL predicts that a plural nominal is interpreted inclusively in downward entailing contexts and questions, and exclusively in upward entailing ones. This is indeed the situation we find in (21)-(24).

Note that the SMH as advanced by Dalrymple et al. (1998), Winter (2001) and Zwarts (2004) is a pragmatic principle, and as such it can be overridden by contextual pressure. If the SMH_PL is indeed responsible for the choice of interpretation for plural nominals, we expect pragmatic pressure to render it inoperative, and make inclusive interpretations available even in upward entailing environments. We argue below that this is indeed the case.

Under the assumption that the speaker knows the facts, the plural form in sentences such as (21a) and (23a) will receive an exclusive interpretation which is informationally stronger than the inclusive one. Furthermore, in these cases there is a single relevant witness for the plural nominal. Under the assumption that the speaker is in full possession of the facts, she should know whether this witness is an atom or a sum. In the first case she should use a singular form because that is the best expression for conveying atomic reference, given the high ranking of the constraint *pl, at (cf. Tableau 1). In the latter case, she should use the plural form, given the equally high ranking of "sg, i/e sum. Under the assumption that the speaker knows what Mary saw/touched then, there is no possibility to weaken (21a) or (23a) to an inclusive plural interpretation under the bidirectional optimization process spelled out in Section 2. But in contexts where the speaker is assumed to in fact lack information concerning the atomic/sum nature of the relevant witness, the SMH_PL no longer requires the exclusive reading and thus inclusive readings of plurals become possible even in upward entailing contexts.

19 Obviously, questions are not generally perceived as downward entailing, but they are subject to the same principle of scale reversal, as evidenced by the well-known fact that NPIs are often licensed in all these environments (cf. Guerzoni \& Sharvit 2007 for a fine-grained discussion of NPI licensing in questions, and Ladusaw 1996 for a general overview of NPI licensing). 
When not in possession of the relevant information, the speaker may be assumed to choose an inclusive plural form precisely because this relatively weak statement (which allows both atoms and sums as possible witnesses) is the strongest one compatible with the incomplete evidence she has. The examples in (28) illustrate just such a case: ${ }^{20}$

(28) a. [Speaker walks into basement, and notices mouse droppings]: Arghh, we have mice!

b. [Speaker walks into unknown house, and notices toys littering the floor]: There are children in this house.

Crucially, the utterances in (28) are felicitous with an inclusive interpretation only in situations in which the speaker finds positive indirect evidence for the presence of mice and children, but has no way of telling how many there are. Although the inclusive interpretation is weaker in upward entailing contexts, it is the strongest possible interpretation of the sentence in a situation of speaker ignorance, where both atomic and sum reference are compatible with the information the speaker is assumed to have. The stronger, exclusive, interpretation in this case is not supported by assumptions about the speaker's state of knowledge, and one prefers to assume that the speaker is obeying the maxim of quality over assuming that she makes the strongest claim her utterance is compatible with. Note that were the speaker to utter (28b) in her own house, and thus be assumed to be in full possession of the facts, the interpretation of the plural is correctly predicted to be exclusive again. Analogous cases are discussed in Zwarts 2004 in terms of a constraint FIT (determining which interpretation fits the context) outranking the constraint STRENGTH. We will not spell out the interpretative tableaux here, but refer the reader to Zwarts 2004 for a way to do so.

\subsection{Plurals in quantificational contexts}

So far, we have proposed that the choice between the two senses of the plural is influenced by monotonicity. In upward entailing contexts, a plural form is normally interpreted as exclusive whereas in downward entailing contexts and questions, scale reversal leads to an inclusive interpretation. This raises the question of what happens in quantificational contexts. ${ }^{21}$

20 We thank one of the participants in 'A bare workshop 2' (LUSH, June 2008) for suggesting the example in (28a).

21 We are grateful to an anonymous reviewer for suggesting to us to discuss the implications of our analysis for plurals in quantificational contexts. We only discuss bare plurals and 
Singulars and Plurals

If the SMH_PL is indeed involved in the choice between the two senses of the plural morpheme we expect, other things being equal, a difference in interpretation of plurals depending on whether they are in the Restrictor or the Nuclear Scope of a distributive universal quantifier because the Restrictor of such a quantifier is downward entailing and the Nuclear Scope is upward entailing. We therefore expect the plural in (29) to favor an exclusive reading: ${ }^{22}$

(29) Each sportsman is wearing gloves.

In order to test this prediction, we carried out a small-scale pilot experiment. We set up a picture-matching task, in which participants were requested to evaluate the Dutch counterpart of (29) in a 'mixed' situation in which some sportsmen were wearing two gloves and others were wearing a single glove. In order to neutralize the effect of expectations, each person in the picture was wearing the correct number of gloves required by their respective sport, so the boxer and the cyclist were wearing two gloves, and the baseball player was wearing a single glove. ${ }^{23}$ Participants strongly rejected (29) as a correct description of such a mixed situation (23 out of 24 said 'no'), confirming the prediction that a plural in the Nuclear Scope of a

definite plurals here, not plural some DPs; plural indefinite determiners will be discussed in Section 4 below.

22 Note that our predictions here differ from those of Spector (2007), where the distinction between the Restrictor and the Nuclear Scope of universal quantifiers is not assumed to be relevant to the choice between inclusive and exclusive plurals. Note also that in order to rule out cumulative and dependent plurals, which are possible in the case of (i) and (ii) we focus on cases involving distributive each.

i. All children were sitting on small chairs.

ii. Unicycles have wheels.

See Zweig (2008) for relevant discussion of dependent plurals.

23 We thank Bert Le Bruyn for his help in designing and carrying out the experiment. The experiment was carried out in Dutch. The singular/plural system in Dutch is parallel to the one in English, and the contrasts between inclusive/exclusive interpretations are easily reproduced in this language. Dutch iedere ('each') proved to be a good universal quantifier to use because it is strongly distributive. One of the control items involved alle ('all'), which easily allows dependent/cumulative interpretations, just like its English counterpart. 24 native speakers served as subjects of the experiment. They were first-year BA students who had just completed an introduction to linguistics, in which the semantics of plurals was not discussed. The test was administered electronically. The participants were presented with a picture and a sentence below it. They were asked to judge whether the sentence gave a correct description of the situation (yes/no). 
distributive universal favors an exclusive interpretation. As expected, the control item All children were sitting on small chairs, where the quantifier all gives rise to a cumulative interpretation of the bare plural small chairs, was widely accepted as the description of a picture with a group of children each sitting on their own small chair (22 out of 24 participants said 'yes'). This preliminary result appears to support the hypothesis that SMH_PL is indeed relevant in choosing between the two senses of [Pl]. Further experimental work is needed in order to conclusively establish this point.

There is a further problem that arises in connection with plurals in the Nuclear Scope of distributive universal quantifiers. It has been noted in the literature that in (30), the definite plural gets an inclusive interpretation (cf. Sauerland et al. 2005):

\section{(30) Each boy invited his sisters}

Sentence (30) can be used to describe a 'mixed' situation, in which each boy invited all the sisters he has, which for some boys means inviting just one sister while for others, it means inviting several. The question that arises is how to account for the difference in interpretation between the bare plural in (29), which seems to favor an exclusive interpretation, and the definite plural in (30), which seems to allow an inclusive reading more readily. Section 2 developed a unified analysis of plural morphology so if bare plurals and definite plurals behave differently here, the difference in our account can only be due to the definite/indefinite contrast. Here we sketch a possible explanation of the contrast in number interpretation based on the contrast in definiteness.

The crucial difference, in our account, between (30) and (29) relates to the contrast between (31) and (32):

(31) Each boy invited his sister

(32) Each boy invited a friend of his

The possessive singular in (31) is interpreted as definite and therefore as referring to the maximal entity that is a sister of the relevant boy. Because of the maximality requirement that is part of the semantics of definite possessives, (31) is false ${ }^{24}$ in a situation in which some boys have one sister and they invited her, while others have more than one sister and they invited all of their sisters. The predicate invited his sister is true only of boys such

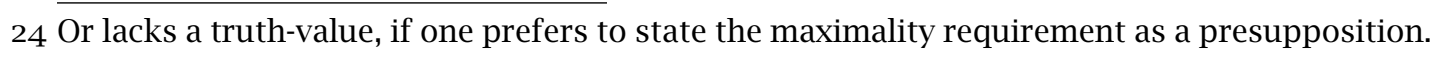


Singulars and Plurals

that the maximal entity that is a sister of theirs is atomic because reference to sum values is not allowed for a singular DP. A mixed situation in which each boy invited the maximal entity that encompasses his sister(s) can be described with a definite plural interpreted inclusively because in that case the maximality requirement of the definite is met as long as for each boy in question there is no sister that remains uninvited. The inclusive plural requirement is met because although some witnesses are atoms there are others which are sums. Note that, as expected, (30) cannot be used in case all boys have a single sister whom they invited (cf. Section 3.3 below). The truth conditions of the definite singular are incompatible with a mixed situation where no sister is left uninvited and some boys have one sister while others have more than one, while the truth conditions of the definite plural, under the inclusive interpretation, are compatible with such a situation.

The indefinite singular on the other hand is truth conditionally compatible with a mixed situation in which some boy invited one friend of his while others invited several. This is because the predicate invited a friend of his can be true of a boy that has several friends and invited only one of them precisely because the indefinite, unlike the definite, has no maximality requirement. If maximality is not part of the semantics of the sentence, the truth conditions of a singular form are compatible with a mixed situation, where some boys invited one of their friends and others invited several.

The contrast between (29) and (30) then is due to the fact that a 'mixed situation' is incompatible with the truth conditions of (31) but compatible with those of (32). Thus, the contextual pressure to override the SMH_PL and give the plural an inclusive interpretation when in the Nuclear Scope of a distributive quantifier is stronger in the case of definites than in the case of indefinites because for definites the singular form is truth conditionally incompatible with a mixed situation while for indefinites this is not so.

We have claimed in this subsection that the choice between the inclusive and exclusive senses of the plural is sensitive to the SMH_PL, which favors the exclusive interpretation of plural forms in ordinary upward entailing environments and the inclusive interpretation in ordinary downward entailing ones. Since the SMH_PL is a pragmatic principle it can be overridden by contextual factors involving cases where the speaker is assumed to describe a 'mixed situation', one where some relevant witnesses are atoms and others are sums. This may arise either because of speaker ignorance of the nature of the relevant witness (as in 28) or because the speaker knows that both types of witnesses are involved and using the plural form is the best way to 
convey this information (as in 30). ${ }^{25}$

\subsection{Implications of the bidirectional analysis for choice of form}

According to the account developed so far, the semantic contrast between singular and plural forms is smallest in downward entailing contexts and questions. In these environments a singular has atomic reference while a plural has inclusive sum reference. Both forms therefore are compatible with atom witnesses. The approach we worked out predicts that a plural form will be appropriate in such contexts only if sum witnesses are relevant because the OT system we set up predicts that the unmarked singular form is optimal in case the witness domain does not include sums and therefore the use of the marked plural is appropriate only in this latter case. In this section we show that this prediction is confirmed and discuss some subtle pragmatic factors that determine whether sum witnesses are relevant in the context or not.

Our approach predicts that even in environments that lead to inclusive interpretations, plural forms are sensitive to the presence of sums among relevant witnesses. We have already seen that this prediction is borne out in cases such as (4a,b) from Farkas 2006 and Spector 2007 respectively, repeated here as (33a) and (33b):

a. Does Sam have a Roman nose/\#Roman noses?

b. Jack doesn't have a father/\#fathers.

In order to account for the contrast between singular and plural forms in examples like (33), Spector assumes an additional modal presupposition associated with (indefinite) plurals that explicitly requires the possibility of a sum witness. The bidirectional OT analysis developed in Section 2.2 and

25 Spector (2007) raises a further empirical issue, namely the interpretation of the plural in exemples such as (i).

i. Exactly one student bought wine bottles to the party.

This sentence is interpreted as claiming that one student brought more than one bottle of wine to the party and no other student brought any bottles of wine to the party. This is a problematic example for us because one and the same plural nominal appears to be interpreted both exclusively (in the positive part of the interpretation) and inclusively (in its negative part). This is a problem we leave open for the time being noting that a full discussion would have to involve both the optimal interpretation of exactly and the way closely related senses of polysemous items interact with it. 
Singulars and Plurals

summed up in Tableau 1 accounts for this contrast without any additional stipulations. The OT analysis does two things simultaneously: it pairs up the singular and plural forms with their optimal interpretation, and at the same time it spells out which forms are optimal to express reference to atoms, to sums, and to a mixture of atoms and sums. Thus, according to Tableau 1 , the optimal expression of exclusive atomic reference is a singular form while in case reference to sums only or to sums as well as atoms is intended the optimal form is a plural. Therefore, we predict that in case the witness domain includes atoms only the plural form will be excluded since $\langle s g$, at $\rangle$ is optimal while $\langle p l$, at $\rangle$ is not. The plural form has to be chosen when sums are the only values in the domain of reference (exclusive plural), or when sums and atoms are included in that domain (inclusive plural) but cannot be used in case the domain of reference excludes sums. Thus, we predict that even in environments in which the inclusive plural interpretation is preferred by the SMH_PL, the singular form will be chosen when the nominal is assumed to take values exclusively from the set of atoms because in such a case the use of the plural form is suboptimal.

How do we know whether sums are relevant in the context? Given that the bidirectional OT analysis spells out the syntax-semantics interface for number, we cannot expect it to determine when reference to sums is intended by the speaker. That requires knowledge of the world and contextual knowledge, and is therefore a matter of pragmatics. ${ }^{26}$ The remainder of this section discusses some of the pragmatic factors that come into play to determine whether reference to sums is assumed to be relevant or not.

Let us consider first the clear cases. As just mentioned, if sums are pragmatically excluded from being possible witnesses for reasons of general world knowledge, as in (33), our analysis predicts that the speaker will choose a singular form and therefore we predict that the use of the plural form in (33a, b) is inappropriate. If, on the other hand, atomic witnesses are excluded for reasons of world knowledge, we predict that a plural form will be appropriate and the singular will not, as confirmed by (34). The singular form in (34b) is infelicitous because a singular form cannot be used if the

26 Although Spector (2007) doesn't work this out in his paper, we take it that he also appeals to contextual knowledge and knowledge of the world in order to explain why the modal presupposition introduced by plural indefinites under his analysis is violated in cases like (33a, b), but not in (3a-c). 
pragmatically restricted domain of reference consists of sums alone.

(34) a. Does a dog have eyes?

b. \#Does a dog have an eye?

These are clear cases since knowledge of the world tells us that people have one nose and that eyes come in pairs. The relevance of sums, inherent to the optimization over forms, accounts for the contrasts in (33) and (34).

There are, however, less clear cases, in which the issue of whether sums are relevant is a more subtle pragmatic matter. Following Farkas (2006), we adopt the hypothesis that in some cases there are default expectations with respect to the atom vs. sum nature of relevant witnesses and that these expectations affect the choice of a singular vs. a plural in environments that are otherwise friendly to inclusive plural interpretations. The account developed here accounts for this effect. To exemplify, note that when it comes to a person having an MA degree, it is simply a default expectation that if they have such a degree, they will have only one. Nothing stops people from piling up multiple MA degrees in their academic career, so sum witnesses in this case are not absolutely excluded. But normally, a person obtains just a single MA degree, so sum witnesses are not among the expected, default witnesses. Under the analysis developed above, we expect that the unmarked way of inquiring whether a person has an MA degree is (35a), with a singular. The question with the plural form is unusual because it explicitly requires one to include sums among possible witnesses. Indeed (35b) suggests that the speaker is inquiring after the possibility of having multiple MA degrees. The use of the plural here signals deviation from default expectations.

(35) a. Do you have an MA degree?

b. Do you have MA degrees?

By contrast, when it comes to a department that has an MA program, the default expectation is that there will be more than one MA student in it. Since sums are now the default witnesses, we expect that the speaker will use a plural in (36a), when inquiring whether the department has an MA program. The choice of the singular in (36b) will be highly unusual, since it signals that sum values are not among the expected witnesses, a situation that is highly unexpected.

(36) a. Are there MA students in your department?

b. \#Is there an MA student in your MA department? 
Singulars and Plurals

The contrast between (35) and (36) is due to the difference in whether one expects sums to be among the relevant witnesses or not. Since the choice of a plural form always requires sum witnesses to be relevant, such a form is natural in (36a) but is unusual in (35b).

The pragmatic relevance of sums also plays a role in (37a), the example most frequently cited as support for the existence of an inclusive reading of the plural.

a. Do you have children?

b. Do you have a child on our baseball team?

The domain from which the nominal chooses witnesses in (37a) is a mixed one since there is no default expectation with regard to how many children a person has. In this case then sums are part of the pragmatically relevant domain and therefore the choice of a plural form is predicted to be appropriate on a tax form, for instance. In (37b) on the other hand, we changed the example so that now the presence of sum values among the default witnesses is removed and, as expected, a singular form is the natural one in a questionnaire in this case.

In the examples discussed so far, common world knowledge shared between speaker and hearer is sufficient to account for the optimal choice of the singular or plural form. The two questions in (38) illustrate that the choice of form may also depend on the context of use.

(38) a. Do you have a broom? (asked in your kitchen after I spilled peas on your floor)

b. Do you have brooms? (asked in a store)

As far as we can see, there are no special expectations about people having one or more than one broom in their house, if they have any. In addition, given the context of use sketched for (38a), the speaker is not expected to need more than one broom. The choice of a singular form is therefore expected, since sum witnesses are not relevant to the situation of use nor is the relevance of sums imposed by common world knowledge. In a store, on the other hand, the relevant witness is by default a sum, since stores normally sell more than one item of a particular type, if they sell that type of item at all. A plural form then is the natural choice in (38b) not because the speaker is interested in buying more than one broom but because of the default sum value expectation associated with the positive answer to her question. 
Further examples that support the generalization that a plural form is used in case sum values are among the default values of a nominal in a particular context, and that singular forms are used when this is not the case are given in (39)-(42):

(39) a. Is Sarah wearing shoes?

b. Is Sarah wearing a hat?

(40) a. Do you have pictures from your wedding?

b. Do you have a picture of Sarah in your wallet?

(41) a. Is there a sauna in this house?

b. Are there nice plants in the garden?

(42) a. Have you bought your Christmas presents already?

b. Have you bought a Christmas present for Aunt Sarah?

Under the bidirectional OT analysis developed in Section 2.2, the singular form is the optimal choice when the domain of reference includes atomic values only (cf. Tableau 1). The inclusive plural tolerates atoms in its domain of reference, but the pair $<\mathrm{pl}$, at $>$ is suboptimal, because of the high ranking of * $p l$, at. So even in questions and under negation, the choice of a plural form requires that sums be included in the domain of the nominal. Sum witnesses must be relevant in whichever way the context supports this (general world knowledge or specific situational knowledge). Therefore, the use of a plural in downward entailing contexts and questions will be natural just in case intended sum reference can be pragmatically justified. The choice between a singular and a plural form in contexts where the interpretations of the singular and the plural overlap thus falls out naturally from our account.

\subsection{Taking stock}

In section 2, we took Horn's division of pragmatic labor to heart, and developed an analysis of the singular/plural contrast in line with the view that unmarked forms are paired up with unmarked meanings, and marked forms with marked meanings. We made no use of a singular feature or morpheme and assigned the plural a polysemous semantics (inclusive and exclusive sum reference).

In Section 3 we invoked the Strongest Meaning Hypothesis to account for the fact that plural forms in ordinary upward entailing environments are normally interpreted exclusively while the best cases of inclusive plurals are found in downward entailing environments and questions. In our analysis 
Singulars and Plurals

the use of a plural form requires sum witnesses to be relevant, a property that we have argued guides the choice between singular and plural forms even in contexts where a plural is interpreted inclusively.

The analysis set up so far meets the desiderata (i)-(iii), formulated in Section 1.4. What remains to be investigated is its cross-linguistic validation (desiderata iv and v). A full-fledged analysis of languages such as Chinese, which lack morphological number altogether, goes beyond the scope of this paper, but note that our set-up is in line with a semantics of Chinese nominals in terms of general number (Rullmann \& You 2003). In contrast with Farkas \& de Swart (2003), we do not take atomic reference to be the default interpretation for argument nominals in general and therefore the current analysis is subtler than our earlier proposal. Crucially, in the current account, the mechanism that associates atomic reference with non-plural forms requires a morphological opposition between singular (unmarked) and plural (marked) nominals in the language. In the next section we turn to the contrast between English and Hungarian DPs in cases where the D lexically entails sum reference. We argue that plural morphology can be absent in such cases precisely because, given the semantics of the $\mathrm{D}$, the contribution of $[\mathrm{Pl}]$ is redundant. The difference between Hungarian and English then is a matter of whether redundant plural morphology is required (English) or prohibited (Hungarian). We work out a full-fledged account of this contrast in Section 4 .

\section{Plural determiners: a cross-linguistic perspective}

So far we have concentrated on the interpretive contribution of the morphological number feature [Pl] when it occurs in nominals in argument position in languages like English, where a morphological distinction between singular and plural nominals is operative. In principle, determiners may also encode information concerning the atom/sum divide. In English, the definite determiner the combines with both singular and plural nouns, so the restriction to atomic or sum reference in the case of definite DPs is solely encoded in morphological information located in NumP. Within the category of indefinite DPs, just like in the case of definites, number interpretation is primarily driven by the morphological singular/plural contrast realized in NumP, though this contrast may be reinforced by determiner choice. A DP headed by several must refer exclusively to sums, while a DP headed by $a(n)$ can only refer exclusively to atoms. The indefinite determiner some, on 
the other hand, is like the definite article in that it has no inherent lexical restrictions pertaining to number interpretation.

The core analysis set up in Sections 2 and 3, illustrated with English, extends to other languages that have a morphological number distinction such as Germanic or Romance languages as well as to non-Indo European language such as Hungarian. In DPs whose determiner does not contribute number information, we expect the effect of the feature [Pl] on the nominal to be the same as in English. We now turn to the data noted in Section 1, where we saw that English and Hungarian contrast in case the determiner is lexically marked for sum reference.

\subsection{A contrast between English and Hungarian}

As outlined in Section 1.4, Hungarian is like English in distinguishing between singular and plural nominals, with the singular remaining unmarked and the plural being marked by the presence of the morpheme - $(a) k$. The facts of number interpretation in English that we discussed so far are parallel in Hungarian and therefore the analysis proposed for English extends to Hungarian as well.

We have seen, however, that there is a crucial difference between the two languages when it comes to DPs whose determiner is lexically marked for sum reference. In English, such DPs are morphologically plural, while in Hungarian they are morphologically singular. We repeat the key relevant Hungarian facts in (43) (see examples in 9 above):

a. három gyerek

[Hungarian]

three child

'three children'

b. sok gyerek

many child

'many children'

These DPs are singular in form (and trigger singular agreement with the $\mathrm{V}$ when in subject position), and yet they have exclusive sum reference. This then is an environment where the semantic contrast between singular and plural forms is neutralized in Hungarian.

What needs an explanation now is why in languages that have a morphological number contrast if the $\mathrm{D}$ is marked for sum reference, we find two options: (i) the language may require the number contrast to be mor- 
Singulars and Plurals

phologically expressed by the presence of the feaute [PI], as in the English three children, many children or (ii) the language may require the number contrast to stay morphologically unexpressed, as in the Hungarian három gyerek, sok gyerek. Note that the difference between these two languages is purely morphological since the semantic interpretation of the relevant DPs is identical. We turn to an account of these facts after we review their significance for competing analyses of number.

\subsection{Implications for the weak/strong singular debate}

If we analyze a determiner such as three as a generalized quantifier expressing existential quantification over sums with cardinality of at least three, the semantics of the DP three children / három gyerek is as in (44). We use [three $\mathrm{NP}]_{s g}$ as shorthand for the Hungarian case, where the DP is singular and there is no plural feature in NumP and thus no plural suffix on $\mathrm{N}$, and [three $\mathrm{NP}]_{p l}$ as shorthand for the English case, where NumP contains the feature [Pl] overtly realized as a suffix on $\mathrm{N}^{27}$
a. $\llbracket[\text { three } \mathrm{NP}]_{s g} \rrbracket=\lambda \mathrm{P} \exists x:\left[{ }^{*} \mathrm{~N}(x) \& \mathrm{P}(x) \&|x| \geq 3\right]$ $(\checkmark$ weak singular)
b. $\llbracket[\text { three } \mathrm{NP}]_{s q} \rrbracket=\lambda \mathrm{P} \exists x:\left[{ }^{*} \mathrm{~N}(x) \& \mathrm{P}(x) \& x \in\right.$ ATOM $\left.\&|x| \geq 3\right]$ (*strong singular)
c. $\llbracket[\text { three } \mathrm{NP}]_{p l} \rrbracket=\lambda \mathrm{P} \exists x:[* \mathrm{~N}(x) \& \mathrm{P}(x) \&|x| \geq 3]$ $(\checkmark$ weak plural)
d. $\llbracket[\text { three } \mathrm{NP}]_{p l} \rrbracket=\lambda \mathrm{P} \exists x:[* \mathrm{~N}(x) \& \mathrm{P}(x) \& x \in$ SUM $\&|x| \geq 3]$ $(\checkmark$ strong plural)

Note that in order to obtain the intended meaning, the fact that the nominal is singular should have no interpretive consequence here. The weak interpretation of singular nominals in (44a) yields the desired interpretation, but the strong singular semantics in (44b) does not, which is why the Hungarian facts are problematic for accounts in which singular forms are semantically potent while being at least compatible with a 'weak singular' approach such

27 The semantics spelled out in (44) may be an oversimplification, given the more fine-grained analyses of the differences in meaning between three children and at least three children that have been offered in the recent literature (cf. Nouwen \& Geurts 2007 and references therein). However, the observations made in these works are tangential to the issues at stake in this paper, because they focus on the role of the determiner, not the singular/plural distinction on the noun. So we ignore these complications here. 
as the one we propose. In our account a singular DP has no inherent atomic reference requirement contributed by a singular feature. It only acquires atomic reference when a number restriction is required and is not provided otherwise. When the nominal is plural, on the other hand, both the weak and the strong plural analyses yield the right interpretations. Under a weak plural account, the plural feature does not contribute any number information, while the determiner requires sum reference given the cardinality requirement, as in (44c). Under the strong plural analysis advocated here, the plural morphology on the noun conveys sum reference in (44d). In this case the semantic contribution of the feature [Pl] is redundant given that exclusive sum reference is entailed by the semantic contribution of the determiner. Thus plural morphology in the DP is redundant when the determiner conveys sum reference, but it is not harmful.

The particular weak singular/strong plural analysis developed in Section 2 derives atomic reference for singular nominals under bidirectional optimization. We crucially need this mechanism in Hungarian as well in order to assign the correct interpretation of ordinary Hungarian singular and plural definite and indefinite DPs such as a gyerek 'the child' and a gyerekek 'the children', which behave just like their English counterparts. But precisely in case the D entails sum reference, the semantic difference between singular and plural forms is neutralized under the assumption that singulars have no semantic import. Due to the semantics of the D, the semantic contribution of the feature $[\mathrm{Pl}]$ is redundant. Because there is no crucial interpretive difference between [three $\mathrm{NP}]_{s g}$ and [three $\left.\mathrm{NP}\right]_{p l}$ the bidirectional optimization over form-meaning pairs spelled out in Section 2 above does not apply to these cases. In view of the semantic equivalence between singular and plural nominals in DPs headed by 'semantically plural' determiners, both English [three $\mathrm{NP}]_{p l}$ and Hungarian [három $\left.\mathrm{NP}\right]_{s g}$ are compatible with the analysis developed so far in this paper. The competition between singular and plural forms is inoperative precisely when there is no meaning contrast that could be encoded by these two forms.

A singular nominal can be associated with sum reference when the possibility of atomic reference is excluded on independent grounds and when the requirement that argument nominals be specified for number reference is satisfied by the D. Note, however, that we predict that the reverse is not possible. Since the plural has a semantic contribution to make, there can be no language just like English or just like Hungarian except that a plural form will be used in case the DP entails atomic reference. If the D excludes sum 
Singulars and Plurals

reference, the use of the marked plural form is predicted to be impossible and thus DPs like *one/a single children are ruled out in both English and Hungarian.

So far we have explained how our approach accounts for the possibility of a singular DP in case the D entails sum reference. What remains to be explained is what dictates the choice between a singular and a plural form in cases where the difference is semantically neutralized. In the languages under consideration the choice between the two forms is not free: English requires the use of the plural in such cases (*three child), while Hungarian requires the use of a singular ("három gyerekek 'three child_pl'). The question we address next is what drives the choice between these two forms in the grammar. We discuss it in some detail because, as far as we know, this issue has not been addressed in the literature.

\subsection{A unidirectional OT analysis}

The contrast between English and Hungarian nominals headed by a semantically plural determiner instantiates a shallow syntactic difference that arises when two forms exist in the language but their semantic difference is neutralized. We view the presence of the feature $[\mathrm{Pl}]$ in the English three children, many children as number agreement, resulting from a requirement that imposes the presence of the feature [Pl] on sum denoting nominals. Its absence in the corresponding Hungarian három gyerek/sok gyerek is seen as a choice dictated by economy considerations that militate against the use of marked forms when redundant. Given that we posit the same semantics for English and Hungarian plural indefinites, such a situation calls for a unidirectional syntactic OT analysis that establishes a more fine-grained distinction within the set of languages with a morphological number distinction. We embed our analysis in an OT typology of number based on classical markedness and faithfulness constraints.

Recall that in Section 2 we exploited the economy constraint *FuNCTN that favours the least number of functional layers on top of the NP. If the plural feature [Pl] lives in the functional projection of NumP and cardinals and indefinite determiners live in $\mathrm{D}$, the presence of such expressions constitutes a violation of *FUNCTN. Such violations are motivated by the need to satisfy faithfulness constraints that are ranked above *FUNCTN. One of these is the constraint FPL, favouring the expression of sum reference in a functional 


\begin{tabular}{|c|c|c|}
\hline$\exists ! x:[x \in$ SUM \& *CHILD $(x)]$ & FPL & $*$ FUNCTN \\
\hline $\begin{array}{l}\text { a gyerek } \\
\text { the child }\end{array}$ & $*$ & $*$ \\
\hline $\begin{array}{l}\text { a gyerekek } \\
\text { the child.PL }\end{array}$ & & $* *$ \\
\hline
\end{tabular}

Tableau 2 expressive optimization for definite plurals (Hungarian)

layer above NP. ${ }^{28}$

(45) FPL: Sum reference must be encoded in the functional structure of the nominal.

Languages that do not have a morphological singular/plural distinction in nominals (such as Mandarin Chinese, cf. Section 1.4 above) rank FPL below *FunCTN (see de Swart \& Zwarts (2008, 2010)). The morphological singular/plural distinction in both English and Hungarian is the result of a grammar in which FPL outranks *FUNCTN. But the formulation of FPL is more general, and allows the expression of number distinctions by other elements in the functional layer above the NP in addition to [PI] in NumP. If we take the Hungarian determiners három, sok, and the other determiners in (10), to satisfy FPL, there is no reason to use the [Pl] feature in NumP. In fact, the markedness constraint *FUNCTN forbids its realization given that in the presence of a determiner that entails sum reference, the feature $[\mathrm{Pl}]$ is redundant. Tableaux 2 and 3 illustrate the optimization process for the plural definite a gyerekek ('the children') and the cardinal három gyerek ('three child').

In both the definite plural and the cardinal plural, we find a violation of *FUNCTN because of the presence of an expression in the functional projection of the nominal. ${ }^{29}$ Given that the input meaning involves sum reference, the high ranking of FPL in the grammar of Hungarian requires satisfaction of this constraint at the expense of the economy constraint

28 Note that the formulation of the constraint FPL here is slightly different from that in de Swart \& Zwarts 2008, 2010, who did not deal with the complexities of cardinals and indefinite plural determiners, but focused on 'plain' definites and indefinites.

29 The presence of the definite determiner $a$ is licensed by a high ranking of the faithfulness constraint FDEF governing the expression of definiteness (see Hendriks et al. 2010: chapter 7, de Swart \& Zwarts 2008, 2010). 
Singulars and Plurals

\begin{tabular}{|ll|c|c|}
\hline$\exists ! x:[x \in$ SUM \& *CHILD $(x)]$ & FPL & $*$ FUNCTN \\
\hline $\begin{array}{l}\text { három } \\
\text { three }\end{array} \quad \begin{array}{l}\text { gyerek } \\
\text { child }\end{array}$ & $*$ \\
\hline $\begin{array}{l}\text { három } \\
\text { three }\end{array} \quad \begin{array}{l}\text { gyerekek } \\
\text { child.PL }\end{array}$ & $* *$ \\
\hline
\end{tabular}

Tableau 3 expressive optimization for plural cardinals (Hungarian)

*FunCTN. The definite article $a$ in Hungarian is similar to English the in that it does not convey number information, so the optimal plural nominal form incurs a second violation of *FUNCTN in Tableau 2. In Tableau 3, there is no reason to use a plural form of the nominal, given that the lexical semantics of the cardinal D három entails sum reference, and may therefore be taken to satisfy FPL. A singular form of the noun is more economical, and is therefore preferred. In OT terms, the use of a singular nominal in combination with a determiner that entails sum reference exemplifies the emergence of the unmarked.

The ranking FPL $\gg *$ FUNCTN is sufficient to account for Hungarian, but does not yet capture the cross-linguistic contrast between Hungarian három gyerek ('three child') and English three children. To capture the intuition that the use of a plural nominal in English in these cases is motivated by agreement in number between the plural determiner and the noun we posit an additional constraint MAXPL.

(46) MAXPL: Mark with [Pl] nominals that have sum reference.

Unlike FPL, MAXPL favours redundant marking of plural morphology within the nominal, at the expense of extra violations of *FUNCTN. The advantage of this multiplication of plural marking is the emphasis on sum reference. MAXPL is inspired by de Swart's (2006, 2010) analysis of negative concord in terms of semantic agreement. ${ }^{30}$ We suggest that the use of plural nominals in contexts in which the determiner already conveys sum reference and thereby satisfies FPL is governed by a high ranking of MAXPL. Under this analysis, the

30 de Swart posits a constraint FNEG requiring faithfulness to the expression of negation, and MAXNEG requiring a reflection of negation on an indefinite argument within the scope of negation on the form of the nominal. The high ranking of MAXNEG in negative concord languages leads to a multiplication of negative forms even in contexts in which they are not needed to satisfy FNEG, and thus convey semantic negation. 


\begin{tabular}{|l|c|c|c|c|}
\hline$\exists x:\left[{ }^{*} \operatorname{CHILD}(x) \&|x| \geq 3\right]$ & FPL & MAXPL & *FUNCTN \\
\hline three child & & $*$ & $*$ \\
\hline three children & & & $* *$ \\
\hline
\end{tabular}

Tableau 4 expressive optimization for plural cardinal meaning (English)

grammar of Hungarian has the ranking FPL $\gg$ *FUNCTN $\gg$ MAXPL, whereas English exemplifies the grammar $\{$ FPL, MAXPL $\} \gg *$ FUNCTN. For Hungarian, the introduction of the new constraint does not affect the optimization patterns spelled out in Tableaux 2 and 3, because MAXPL is ranked too low to have an effect. For English, the new ranking leads to the optimal form three children for the expression of cardinality information over children, as illustrated in Tableau 4.

Sum reference is entailed by the cardinal determiner three, so FPL is satisfied, just like in Hungarian. However, the constraint MAXPL maximizes the expression of plurality by forcing it to appear in NumP as well. The high ranking of this constraint in English leads to a preference of agreement between the determiner and the nominal over a more economical form. In Hungarian, the constraint MAXPL is ranked below *FUNCTN, where it is inoperative.

Independent support in favor of our analysis comes from L1 acquisition. Children acquiring a double negation language such as standard English sometimes go through a phase in which they multiply negation as if they were speaking a negative concord language. Along similar lines, Hungarian children sometimes mistakenly use the form *három gyerekek ('three children') before they acquire the grammatical három gyerek ('three child'). Even though anecdotal, this evidence suggests that child grammar favours agreement both for negation and number marking.

The analysis of the contrast between Hungarian and English is not in conflict with the bidirectional optimization process developed in Section 2 , but rather, it covers a niche where the competition in form evades the competition in meaning. With inherently plural determiners, the determiner entails sum reference for the nominal as a whole, and thus makes irrelevant the semantic competition between singular and plural forms. In languages with a morphological singular/plural distinction, this creates room for a new competition between unmarked (singular) and marked (plural) forms. In the absence of a difference in meaning, the optimal expression is selected 
Singulars and Plurals

on purely formal grounds. The competition here is between economy of form (exemplified by Hungarian), and agreement between D and its sister (exemplified by English). ${ }^{31}$

We conclude that Hungarian and English are both members of the class of languages with a full-fledged morphological singular/plural distinction in nominals, and a grammar in which FPL is ranked above *FUNCTN. However, there are subclasses within this general class, that exploit contrasts in form for other purposes than to express a distinction between atomic and sum reference. Given that agreement in number between determiner and its sister is available only in languages with a morphological singular/plural distinction (instantiating FPL $\gg *$ FUNCTN), we predict such subtleties not to occur in languages lacking number morphology.

\section{Conclusion}

The semantics and pragmatics of the plural in languages with a morphological number distinction has been a problem on the semantics agenda since McCawley (1981) raised the question of how to reconcile the morphological markedness of the plural, with its seemingly unmarked semantics. The main point of this paper is to propose a way of resolving this tension, and maintain Horn's division of pragmatic labor for number in natural language.

Recent accounts of number interpretation, stemming from Krifka (1989), accept this tension, and attempt to explain it (Bale et al. in press). Recall that Sauerland et al. (2005) rests on the assumption that singular forms are marked with a singular feature that requires atomic reference while plural forms involve a feature with no semantic contribution while in Spector 2007 singulars have the same 'strong' semantics while the plural feature is assigned a weak semantics equivalent to 'at least one'. In Sauerland et al. 2005 plural forms have sum reference because the existence of the semantically more specific singular form blocks their use in case of atomic reference. In Spector 2007 a similar result is achieved using higher order implicatures.

The approach we developed here shares with these previous proposals the insight that number interpretation requires a competition-based account

31 We use the term 'agreement' here to cover not only cases where morphological features are shared but also cases where the presence of a morphological feature on one node is connected to the presence of a semantic constraint on another. Our account therefore is compatible with a morphological treatment of English which does not use [Pl] as a feature on Ds. 
and involves the blocking of one form by the existence of the other. We couch it in terms of bidirectional Optimality Theory because this framework is particularly suitable for capturing the phenomenon of blocking. In Bidirectional OT, the syntax-semantics interface is defined in terms of optimization over form-meaning pairs, making use of a mechanism that selects the optimal meaning for a particular form, and the optimal form for a particular meaning.

The crucial novelty of this paper is that it reverses the direction of blocking. We have worked out a weak singular/strong plural account of number interpretation for the languages under consideration, in which there is no singular feature and no special semantics associated with singular forms while plural forms are assumed to involve a semantically potent plural feature. The main conceptual advantage of such an approach is that it reconciles semantic and formal markedness when it comes to number interpretation and explains why in the languages under consideration there is a plural morpheme but no special singular marking. The main empirical advantage of our approach is that it predicts the possibility of using singular forms with sum reference in case the semantic distinction between singular and plural forms is neutralized, a possibility that is realized in Hungarian.

We have adopted the abstract system developed in Mattausch 2005, 2007 and adapted it to the morphology and semantics of number. Crucially, we have suggested that the relevant semantic markedness parameter for the languages under consideration is the distinction between the conceptually unmarked atom reference and the conceptually marked inclusive or exclusive sum reference.

The system we propose associates marked plural forms with marked sum reference interpretation and unmarked singular forms with unmarked atomic reference. The marked plural form is associated with the requirement that sums be included among possible witnesses of the nominal, a requirement that is realized by giving the feature $[\mathrm{Pl}]$ a polysemous semantics, with one sense reserved for the exclusive interpretation and the other for the inclusive interpretation. The unmarked singular form has no inherent semantics, but under bidirectional optimization, it takes the complementary meaning of the marked plural which is exclusive sum interpretation.

We have proposed a weak singular/strong plural approach in which formal and interpretational markedness are parallel, a pattern we find elsewhere in natural language. At the same time, our proposal meets the challenge posed by the existence of plural forms interpreted inclusively. In fact, once we adopt the view that having sum reference is the conceptually marked 
interpretation, the account makes us expect plural forms to be used both for inclusive and exclusive sum reference. What the system rules out, however, is a plural form used when the existence of a sum witness is excluded. This is a welcome result. The relevance of sum values to all uses of plurals in the languages under consideration follows from our analysis without having to assume a strong semantics for singulars (as in Sauerland et al. 2005) or having to add a special modal presupposition for plurals (as in Spector 2007).

In our approach, just as in previous proposals, the competition between the inclusive and the exclusive interpretation of plural forms is decided by pragmatic rather than semantic factors. We have relied on applying the Strongest Meaning Hypothesis to the interpretation of the plural, which correctly predicts that plural forms will be interpreted exclusively in ordinary upward entailing contexts and inclusively when under the scope of negation or in the Restrictor of conditionals or distributive universals. But even in contexts in which inclusive readings are permitted, sum reference must be relevant. We have seen that subtle pragmatic factors determine in which contexts and situations sum reference is relevant.

The main theoretical contribution of the account we developed here is that it respects the Horn pattern while at the same time accounting for the existence of inclusive plurals as well as for the main dividing line between inclusive and exclusive plurals. We have shown here that such an account is both possible and desirable. On the empirical side, our approach has the advantage of accounting for the relevance of sum reference with plural forms, as well as predicting the possibility of singular nominals with sum reference just in case sum reference is imposed by D independently of what is found in NumP. This is indeed the case of Hungarian singular DPs such as sok gyerek 'many child'. We have presented an account of these facts that treats the singular form of these DPs as the result of the language valuing functional economy over the pressure to mark sum reference uniformly with the feature [Pl]. The obligatory plural forms of such DPs in English is due to this language valuing uniform [Pl] marking of sum denoting DPs higher than functional economy. The account we propose then meets what we take to be the main challenges number semantics faces without having to rely on any tools that are not independently motivated. 
Farkas and de Swart

\section{References}

Bale, Alan, Michaël Gagnon \& Hrayr Khanjian. in press. On the relationship between morphological and semantic markedness: the case of plural morphology. Journal of Morphology http://linguistics.concordia.ca/bale/ pdfs/Morphology\%2opaper.pdf.

Beaver, David. 2002. The optimization of discourse anaphora. Linguistics and Philosophy 27(1). 3-56. doi:10.1023/B:LING.ooooo10796.76522.7a.

Beaver, David \& Hanjung Lee. 2004. Input-output mismatches in OT. In Reinhard Blutner \& Henk Zeevat (eds.), Optimality theory and pragmatics, 112-153. Palgrave/MacMillan. https://webspace.utexas.edu/dib97/ publications.html.

Blutner, Reinhard. 1998. Lexical pragmatics. Journal of Semantics 15(2). 115-162. doi:10.1093/jos/15.2.115.

Blutner, Reinhard. 200o. Some aspects of optimality in natural language interpretation. Journal of Semantics 17(3). 189-216. doi:10.1093/jos/17.3.189.

Blutner, Reinhard. 2004. Pragmatics and the lexicon. In Laurence Horn \& Gregory Ward (eds.), Handbook of pragmatics, 488-514. Oxford: Blackwell. Chierchia, Gennaro. 2004. Scalar implicatures, polarity phenomena and the syntax/pragmatics interface. In A. Belletti (ed.), Structures and beyond, 39-103. Oxford: Oxford University Press.

Chierchia, Gennaro. 2006. Broaden your views: implicatures of domain widening and the "logicality" of natural language. Linguistic Inquiry 37(4). 535-590. doi:10.1162/ling.2006.37.4.535.

Chierchia, Gennaro, Danny Fox \& Benjamin Spector. 2008. The grammatical view of scalar implicatures and the relation between semantics and pragmatics. In Klaus von Heusinger, Claudia Maienborn \& Paul Portner (eds.), Semantics. An international handbook of natural language meaning, Mouton de Gruyter, New York, NY.

Cohen, Ariel. 2005. More than bare existence: An implicature of existential bare plurals. Journal of Semantics 22(4). 389-400. doi:10.1093/jos/ffho31.

Corbett, Greville G. 200o. Number. Cambridge University Press, Cambridge. doi:10.2277/0521640164.

Dalrymple, Mary, Makoto Kanazawa, Yookyung Kim, Sam Mchombo \& Stanley Peters. 1998. Reciprocal expressions and the concept of reciprocity. Linguistics and Philosophy 21(2). 159-210. doi:10.1023/A:1005330227480.

Farkas, Donka F. 2006. The unmarked determiner. In Svetlana Vogeleer \& Liliane Tasmowski de Rijk (eds.), Non-definiteness and plurality, 81-106. 
Singulars and Plurals

John Benjamins, Amsterdam.

Farkas, Donka F. \& Henriëtte E. de Swart. 2003. The semantics of incorporation: from argument structure to discourse transparancy. CSLI Publications, Stanford: CA.

Farkas, Donka F. \& Draga Zec. 1995. Agreement and pronominal reference. In Guglielmo Cinque \& Giuliana Giusti (eds.), Advances in Roumanian linguistics, 83-101. John Benjamins, Amsterdam.

Fauconnier, Gilles. 1979. Implication reversal in natural language. In Franz Guenthner \& Siegfried J. Schmidt (eds.), Formal semantics and pragmatics for natural languages, Reidel.

Feigenson, Lisa \& Susan Carey. 2003. Tracking individuals via object files: evidence from infants' manual search. Developmental Science 6(5). 568584. doi:10.1111/1467-7687.00313.

Feigenson, Lisa \& Susan Carey. 2005. On the limits of infants' quantification of small object arrays. Cognition 97(3). 295-313. doi:10.1016/j.cognition.2004.09.010.

Feigenson, Lisa, Susan Carey \& Marc Hauser. 2002. The representations underlying infants' choice of more: object files versus analog magnitudes. Psychological Science 13(2). 150-156. doi:10.1111/1467-9280.00427.

von Fintel, Kai. 1999. NPI-licensing, Strawson entailment and contextdepencency. Journal of Semantics 16(2). 97-148. doi:10.1093/jos/16.2.97. Greenberg, Joseph. 1966. Language universals. Mouton, the Hague.

Guerzoni, Elena \& Yael Sharvit. 2007. A question of strength: on NPIs in interrogative clauses. Linguistics and Philosophy 30(3). 361-391. doi:10.1007/s10988-007-9014-X.

Hauser, Marc, Susan Carey \& L.B. Hauser. 2000. Spontaneous number representation in semi-free-ranging rhesus monkeys. In Royal society of london: Biological sciences, vol. 267, 829-833. doi:10.1098/rspb.2000.1078.

Heim, Irene. 1991. Artikel und Definitheit. In Arnim von Stechow \& Dieter Wunderlich (eds.), Handbuch der Semantik, Berlin: de Gruyter.

Hendriks, Petra, Helen de Hoop, Henriëtte de Swart \& Joost Zwarts. 2010. Conflicts in interpretation. Equinox Publishing (in press), preprint http: //www.let.rug.nl/ hendriks/conflict.htm.

Horn, Laurence. 2001. A natural history of negation. CSLI Publications, Stanford: CA.

Ionin, Tania \& Ora Matushansky. 2006. The composition of complex cardinals. Journal of Semantics 23(4). 315-36o. doi:10.1093/jos/ffloo6.

Jäger, Gerhard. 2003. Learning constraint sub-hierarchies. In Reinhard 
Farkas and de Swart

Blutner \& Henk Zeevat (eds.), Pragmatics and optimality theory, 251-287. Houndmills: Palgrave MacMillan.

Jakobson, Roman. 1939. Signe zéro. In Mélanges de linguistique offerts à charles bally, Genève (also in Selected Writings II).

Kamp, Hans \& Jan van Eijck. 1996. Representing discourse in context. In Johan van Benthem \& Alice ter Meulen (eds.), Handbook of logic and linguistics, 179-237. Amsterdam: Elsevier.

Kamp, Hans \& Uwe Reyle. 1993. From discourse to logic. Dordrecht: Kluwer Academic Publishers.

Kester, Ellen-Petra \& Christina Schmitt. 2007. Papiamentu and Brazilian Portuguese: a comparative study of bare nominals. In Marlyse Babtista \& Jacqueline Guéron (eds.), Noun phrases in creole languages: a multifaceted approach, Amsterdam: Benjamins.

Kirby, Simon \& Jim Hurford. 1997. The evolution of incremental learning: language, development and critical periods. In Antonella Sorace, Caroline Heycock \& Richard Shillcock (eds.), Gala '97 conference on language acquisition, HCRC, Edinburgh University.

Kouider, Sid, Justin Halberda, Justin Wood \& Susan Carey. 2006. Acquisition of English number marking: the singular-plural distinction. Language Learning and Development 2. 1-25. doi:10.1207/s15473341lldo201_1.

Krifka, Manfred. 1989. Nominal reference, temporal constitution and quantification in event semantics. In Renate Bartsch, Johan van Benthem \& Peter van Emde Boas (eds.), Semantics and contextual expression, Dordrecht: Foris publication.

Krifka, Manfred. 1995. Common nouns: a contrastive analysis of English and Chinese. In Greg N. Carlson \& Francis Jeffry Pelletier (eds.), The generic book, 398-411. Chicago University Press. http://amor.rz.hu-berlin.de/ $\sim \mathrm{h} 2816 \mathrm{i} 3 \mathrm{x} /$.

Kwon, Song-Nim \& Anne Zribi-Hertz. 2006. Bare objects in Korean: (pseudo)incorporation and (in)definiteness. In Svetlana Vogeleer \& Liliane Tasmowski de Rijk (eds.), Non-definiteness and plurality, 107-132. John Benjamins, Amsterdam.

Ladusaw, William. 1996. Negation and polarity items. In Shalom Lappin (ed.), The handbook of contemporary semantic theory, 321-341. Oxford: Blackwell.

Lakoff, Robin. 2000. The language war. University of California Press, Berkeley.

Link, Godehard. 1983. The logical analysis of plural and mass nouns: a lattice- 
Singulars and Plurals

theoretic approach. In Rainer Bäuerle, Christoph Schwarze \& Arnim von Stechow (eds.), Meaning, use and interpretation of language, 302-323. Berlin: de Gruyter.

Mattausch, Jason. 2005. On the optimization and grammaticalization of anaphora: Humboldt University Berlin, published as ZAS Papers in Linguistics 38 dissertation. http://www.zas.gwz-berlin.de/mitarb/homepage/ mattausch/Dissertation-Mattausch.pdf.

Mattausch, Jason. 2007. Optimality, bidirectionality and the evolution of binding phenomena. Research on Language and Computation 5(1). 103131. doi:10.1007/s11168-006-9018-7.

McCawley, Jim. 1981. Everything that linguists have always wanted to know about logic (but were ashamed to ask). Chicago: University of Chicago Press (2nd edition 1993).

Nouwen, Rick \& Bart Geurts. 2007. At least et al.: the semantics of scalar modifiers. Language 83. 533-559. http://ncs.ruhosting.nl/bart/.

van Rooij, Robert. 2004. Signalling games select Horn strategies. Linguistics and Philosophy 27(4). 493-527. doi:10.1023/B:LING.00ooo24403.88733.3f.

Rullmann, Hotze. 2003. Bound-variable pronouns and the semantics of number. In Western conference on linguistics, vol. 14, 243-254. WECOL 2002. http://semanticsarchive.net/Archive/DM3ODkoN/.

Rullmann, Hotze \& Aili You. 2003. General number and the semantics and pragmatics of indefinite bare nouns in Mandarin Chinese. ms. UBC. http: //semanticsarchive.net/Archive/jhlZTY3Y/.

Sauerland, Uli. 2003. A new semantics for number. In Rob Young \& Yuping Zou (eds.), Salt 13, vol. 13, 258-275. CLC publications. http://semanticsarchive. net/Archive/TMoYjdiO/salto3paper.pdf.

Sauerland, Uli. 2008. On the semantic markedness of phi-features. In Harbour, D. et al. (ed.), Phi theory, 57-83. Oxford: Oxford University Press. http: //www.zas.gwz-berlin.de/home/sauerland/downloads.html.

Sauerland, Uli, J. Anderssen \& J. Yatsushiro. 2005. The plural is semantically unmarked. In Stephan Kepser \& Marga Reis (eds.), Linguistic evidence, de Gruyter. doi:10.1515/9783110197549.413.

Spector, Benjamin. 2007. Aspects of the pragmatics of plural morphology: On higher-order implicatures. In Uli Sauerland \& Penka Stateva (eds.), Presuppositions and implicatures in compositional semantics, 243-281. Palgrave/MacMillan. http://lumiere.ens.fr/ bspector/.

de Swart, Henriëtte. 2006. Marking and interpretation of negation: a bidirectional OT approach. In Raffaella Zanuttini, Héctor Campos, Elena 
Herburger \& Paul Portner (eds.), Negation, tense and clausal architecture: Cross-linguistic investigations, 199-218. Georgetown: Georgetown University Press. http://www.let.uu.nl/ Henriette.deSwart/personal/negot.pdf. de Swart, Henriëtte. 2010. Expression and interpretation of negation: an OT typology. Dordrecht: Springer (in press).

de Swart, Henriëtte \& Joost Zwarts. 2008. Article use across languages: an OT typology. In Atle Grønn (ed.), Sinn und Bedeutung, vol. 12, 628-644. University of Oslo.

de Swart, Henriëtte \& Joost Zwarts. 20o9. Less form, more meaning: why bare nominals are special. Lingua 119(2). 280-295. doi:10.1016/j.lingua.2007.10.015.

de Swart, Henriëtte \& Joost Zwarts. 2010. Optimization principles in the typology of number and articles. In Bernd Heine \& Heiko Narrog (eds.), Handbook of linguistic analysis, Oxford: Oxford University Press. http://www. let.uu.nl/ Henriette.deSwart/personal/oupdeSwartZwartsmayo8.pdf.

Winter, Yoad. 2001. Plural predication and the strongest meaning hypothesis. Journal of Semantics 18(4). 333-365. doi:10.1093/jos/18.4.333.

Wood, Justin, Sid Kouider \& Susan Carey. 2004. The emergence of singular/plural distinction. Poster presented at the biennial International Conference on Infant Studies. http://www.wjh.harvard.edu/ lds/index. html?carey.html.

Zwarts, Joost. 2004. Competition between word meanings: the polysemy of around. In Sinn und Bedeutung, 349-36o. Konstanz. http://www.let.uu. $\mathrm{nl} /$ users/Joost.Zwarts/personal/.

Zweig, Eytan. 2008. Dependent plurals and plural meaning: NYU dissertation. http://www-users.york.ac.uk/ ez506/.

Donka Farkas

Department of Linguistics

University of California at Santa Cruz

Stevenson College

1156 High Street

Santa Cruz, CA 95064, USA

farkas@ucsc.edu
Henriëtte de Swart

Department of Modern Languages

Utrecht University

Trans 10

3512 HD Utrecht

The Netherlands

h.deswart@uu.nl 